\title{
Effects of diameter distribution errors on stand management decisions according to a simulated individual tree detection
}

\author{
Jari Vauhkonen ${ }^{1,2}$
}

Received: 14 May 2019 / Accepted: 10 January 2020 / Published online: 17 March 2020

(C) The Author(s) 2020

\begin{abstract}
- Key Message Tree-level forest inventory data are becoming increasingly available, which motivates the use of these data for decision-making. However, airborne inventories carried out tree-by-tree typically include systematic errors, which can propagate to objective function variables used to determine optimal forest management. Effects of under-detection focused on the smallest trees on predicted immediate harvest profits and future expectation values were assessed assuming different sites and interest rates. Management decisions based on the erroneous information caused losses of 0-17\% of the total immediate and future expected income of Scots pine stands.

- Context Optimal decisions on how to manage forest stands can depend on the absence or presence of intermediate and understory trees. Yet, these tree strata are likely prone to inventory errors.

- Aims The aim of this study is to examine implications of making stand management decisions based on data that include systematic errors resembling those typically observed in airborne inventories carried out tree-by-tree.

- Methods Stand management instructions were developed based on theoretical diameter distribution functions simulated to have different shape, scale, and frequency parameters corresponding to various degrees of under-detection focused on the smallest trees. Immediate harvest income and future expectation value were derived based on various management alternatives simulated. - Results Errors in diameter distributions affected the predicted harvest profits and future expectation values differently between the simulated alternatives and depending on site type and interest rate assumptions. As a result, different alternatives were considered as optimal management compared to the use of the error-free reference distributions. In particular, the use of no management or most intensive management alternatives became preferred over alternatives with intermediate harvesting intensities. Certain harvesting types such as thinning from below became preferred more often than what was optimal. The errors did not affect the selection of the management alternative in $71 \%$ of the simulations, whereas in the remaining proportion, relying on the erroneous information would have caused losing $2 \%$, on average, and $17 \%$ at maximum, of the total immediate and future expected income.

- Conclusion The effects above might not have been discovered, if the results were validated for inventory totals instead of separately considering the immediate and future income and losses produced by the erroneous decisions. It is recommended not to separate but to integrate the inventory and planning systems for well-informed decisions.
\end{abstract}

Keywords Forest inventory $\cdot$ Forest management planning $\cdot$ Single-tree remote sensing $\cdot$ Uncertainty $\cdot$ Weibull distribution

Handling Editor: David Drew

Contributions of the co-authors J.V. is the sole author.

This paper is part of the topical collection Frontiers in Modelling Future Forest Growth, Yield and Wood Properties

Jari Vauhkonen

jari.vauhkonen@helsinki.fi

1 Bioeconomy and Environment Unit, Natural Resources Institute Finland (Luke), Yliopistokatu 6, FI-80100 Joensuu, Finland

2 Present address: Department of Forest Sciences, University of Helsinki, Latokartanonkaari 7, FI-00014 Helsinki, Finland

\section{Introduction}

In the Nordic countries, forestry decisions are most often made by non-industrial private owners, who manage their forests according to tactical management plans prepared to meet the owners' objectives at the forest holding level. If economic objectives are included, those are usually met by growing trees to be harvested as commercial timber assortments. Size, quality, and species determine the possibilities of bucking tree stems into logs for sawing or pulpwood. Even if harvesting and long-distance transport (based on 
mechanized cut-to-length methods) are usually carried out as subcontracting, the owners who seldom are forestry professionals need instructions to schedule the harvests over rotation periods to optimize income from wood production. The management practices should specifically be optimized for sawlog production, because a cubic meter of sawlog is about three times more valuable than a cubic meter of pulpwood (according to average stumpage prices paid in Finland in the beginning of 2019).

In Finland since around 2010, information on forest production possibilities for planning tasks described above has been based on data acquired by means of remote sensing (Maltamo and Packalen 2014). With slight variations in sources and combinations of airborne and field data according to the requirements of different planning systems (cf. Næsset 2014), similar inventories are proposed for planning forest resources management also elsewhere in the northern boreal forest zone (e.g., Bourgeois et al. 2018). Regardless of the data source, the information is unlikely perfect in that it can contain errors that distort the description of the current forest status, resulting to suboptimal decisions. It is consequently informative for decision-makers to measure the utility of new data in terms of the expected value of information (Kangas 2010; Kangas et al. 2014) rather than or in addition to the statistical accuracy of new data. For example, according to a metaanalysis of five studies (Kangas et al. 2018a), a unit increase in the relative root mean squared error of total volume increased losses due to suboptimal decisions by $4.4 € / \mathrm{ha}$, on average. Factors affecting optimal quality of inventory data have further been addressed by Mäkinen et al. (2012), Kangas et al. (2015), Eyvindson et al. (2017), and Ruotsalainen et al. (2019).

Two ongoing trends in Finland, one related to the implementation of forest management and another one to the implementation of the management inventories, are likely to have an effect on the value of information of remotely sensed data for stand management decisions that has not been previously addressed. First, forest legislation and, consequently, official management instructions were reformed in 2014 to allow more flexibility in silvicultural practices. It is reasonable to expect that an increasing number of forests will be managed with practices other than conventional rotation forestry or even-aged management, for various reasons described by Nieminen et al. (2018) and Vauhkonen and Packalen (2019). Especially, continuous cover forestry has been suggested to produce more profits for forest owners with a high alternative rate of return (Tahvonen 2009; Laiho et al. 2011; Pukkala 2016a) and higher levels of multiple ecosystem services (Pukkala 2016b; Peura et al. 2018). Another recently adopted direction is any-aged forestry (Pukkala et al. 2014a), in which an explicit choice between management systems is not made. It can be instructed using a set of functions that define the need, type, and intensity of a treatment; despite simplistic formulation, the use of such functions was found to result in equally good management schedules as optimization (Pukkala 2018).

Secondly, remotely sensed data can be segmented to small computation units corresponding to tree groups or even individual trees (e.g., Koch et al. 2014; Lindberg and Holmgren 2017). Mäkinen et al. (2010) and Vastaranta et al. (2011) analyzed various error sources related to individual tree detection and delineation with respect to the accuracy of producing stand variables for even-aged management decisions and concluded that accurate tree detection was more important than diameter and height estimation. However, neither Mäkinen et al. (2010) nor Vastaranta et al. (2011) had observed tree data but used a Monte Carlo approach to simulate the errors as a function of relative tree size. Other studies indicate that the success of detecting trees with a given relative size can vary depending on stand structure parameters such as canopy cover, tree density, and spatial pattern (Falkowski et al. 2008; Larsen et al. 2011; Vauhkonen et al. 2012). Furthermore, decision variables for optimizing even-aged management, i.e., rotation lengths and thinning schedules, are based on aggregate basal area, dominant height, and median tree diameter, and there is a probability for correct decisions even if these variables are erroneous (Kangas et al. 2011). On the other hand, the planning of continuous cover forestry would require knowledge on the species and size of small-sized understory trees occurring below the dominant tree canopy, because the future stand development heavily relies on those trees.

The study of Bergseng et al. (2015) appears to be the only one to consider net present value losses due to incorrect management decisions based on actual tree detection data. Their only decision variable was the timing of the final felling, on which the decisions were made applying one interest rate (3\%). They found out that the use of observed diameter distributions reduced financial losses compared with the use of diameter distributions modeled from mean tree variables; however, distributions predicted by means of area-based methods yielded less losses than those based on observing individual trees. Bergseng et al. (2015) used tree-level growth models and also Mäkinen et al. (2010) had found a tree-level simulator to be more precise and less prone to errors than a stand-level simulator, whereas the choice to use either tree- or stand-level growth models did not become significant in the meta-analysis of Kangas et al. (2018a). It can, however, be questioned how well the earlier studies isolate the effects of errors in input tree data vs. error sources and potential error interactions originating from applying long growth modeling chains. The studies mentioned above did not consider unevenaged management alternatives, whereas studies involving tree-level operation models (individual tree selection in 
harvests that could result to uneven-aged stand structures as in Pukkala and Miina 1998; Pukkala et al. 2015; Vauhkonen and Pukkala 2016; Wing et al. 2019) did not consider the effects of inventory errors on the tree selection.

Making forest management decisions in detailed spatial scales is referred to as "precision forestry" (e.g., Giannetti 2017). However, combining visions of tree-level precision forestry with the reality of tree data acquisition seems to produce an interesting dilemma. Making tree-level management decisions could be motivated by avoiding the choice between even- or uneven-aged management (cf. Vauhkonen and Pukkala 2016), which is a constraint that never improves the profitability of forest management (see also Haight and Monserud 1990a,b). The increased availability of tree-level forest inventory data seemingly supports the possibilities for such decisions. Yet, there is a clearly identifiable knowledge gap in how well remotely sensed data suffice for information needs of uneven-aged management (see also Köhl and Baldauf 2012). Based on earlier literature, individual tree detection can be expected to describe the dominant tree layer accurately (Peuhkurinen et al. 2007; Vauhkonen et al. 2014), but miss trees located in particular in intermediate and understorey layers (e.g., Duncanson et al. 2014), resulting to incorrectly predicted distributions of diameters (Peuhkurinen et al. 2011; Vauhkonen and Mehtätalo 2015). The erroneous information on the intermediate and understory strata can propagate subsequent management decisions. It could be feasible for a forest owner to utilize understory trees as the next tree generation for uneven- or any-aged forestry. Yet, missing the information on the small trees could result to always proposing alternatives based on artificial regeneration and, consequently, even-aged management. Benefits from tree-level inventories may therefore differ for timber cruisers and forest owners and planning tasks requiring considerations of uneven-aged management alternatives.

The aim of this study is to examine the implications of making stand management decisions based on erroneous inventory data. Growing stock underestimation that is typically reported as a result of airborne inventories carried out tree-by-tree was under specific attention. The study was carried out solely by means of simulations of theoretical diameter distribution functions with different shape, scale, and frequency parameters corresponding to various degrees of under-detection focused on the smallest trees. Immediate and future harvesting income was derived for the different distributions based on simulated management. The management alternatives included typical even-aged practices, but also thinnings from above that can be applied to, inter alia, converting even-aged stands towards uneven-aged forest structures. Only the first management action was simulated with an aim not only to distinguish the effects of input data from those originating along further modeling but also to consider the magnitudes by which different site types and interest rates could affect the decisions in addition to tree data.

\section{Material and methods}

\subsection{Simulated diameter distributions}

The simulations were based on altogether 40 stands located in Eastern Finland and studied by Vauhkonen and Mehtätalo (2015). Scots pine (Pinus sylvestris L.) was considered to be the only tree species, because also in the real world, $\geq 95 \%$ of the total basal area of each stand was represented by this species. The tree lists for the simulations can be reproduced by running code prepare_data. $R$ (Annex 1) that implements the steps described below using the distribution parameters provided as Annex 2 Table 1.

The diameter distributions of the stands were modeled using the two-parameter form of the Weibull function. Assuming the distributions to follow the Weibull functions was motivated for this exercise, because their parameters can be easily made available with codes producing the entire simulation (Annexes 1 and 2 Table 1; Vauhkonen 2019) for reproducibility and sensitivity analyses. Yet, the effects of different management should become clear enough even with simple distribution forms. Four realizations of the diameter distribution were simulated for each stand as follows:

- Two-parameter Weibull functions with shape and scale parameters resembling maximum likelihood fit of these functions to the field-measured tree diameters were considered the reference distributions. The total absolute frequency of the distributions was scaled to correspond with the number of field-measured trees.

- Two-parameter Weibull functions with shape and scale parameters resembling maximum likelihood fit of these functions to tree diameters predicted as a result of treelevel interpretation of airborne laser scanning data were considered typical error-distorted distributions obtainable by remote sensing. The total absolute frequency of the distributions was scaled to correspond with the number of trees detected. In the tree detection and prediction chain, detailed by Vauhkonen and Mehtätalo (2015), individual trees were isolated combining an adaptive filtering of local height maxima and watershed segmentation (Pitkänen et al. 2004; Pitkänen 2005). Tree diameters were predicted by a locally fitted model with maximum height and radius of the tree segments as predictors.

- Linear interpolation was applied to the above distribution parameters to generate a wider set of distributions that varied in terms of the shape, scale, and frequency. 
The purpose of including distributions obtained by means of linear interpolation was to describe an improved or decremented individual tree detection performance. The first case could reflect a higher success rate of detecting trees due to improved algorithms (cf. Kansanen et al. 2019) and the latter a lower rate due to using poorer remote sensing material, for instance. As illustrated in Fig. 1 (left), the interpolation was carried out by using the reference distribution parameters as origin and projecting the shape, scale, and frequency values linearly from the origin toward the values of these parameters that produced the error-distorted distribution of a stand. To obtain two realizations representing a better and a worse fit of the distribution than the typical error-distorted one, the vectors were sampled for their midpoints and endpoint + midpoints, respectively; i.e., the latter is an extrapolation of the distribution parameters. Figure 1 (right) shows how the simulated distributions compare with each other in the case of an example stand.

The continuous distribution functions were discretized to obtain a set of tree diameters corresponding to the total number of trees in a hectare of forest as follows. The (relative) quantile value of a distribution was examined in steps of 0.01 , and the diameter values increasing the tree number by at least a whole integer from the previous step were recorded as the diameters of the stand. The tree lists were added with tree heights by applying the Näslund height function to the full list of diameters. The parameters of the Näslund function were based on fitting a fixed, population-level model to separate data using the R-package Imfor (Mehtatalo 2017). The model fitting data was the default dataset spati of lmfor that is from another area located within a geographic distance of less than $100 \mathrm{~km}$ from the studied area.

Figure 2 presents a comparison of central statistics of the forest data simulated. The Weibull scale, shape, and frequency parameters of the erroneous distributions clearly diverted away from the reference one. The basal area-weighted mean diameter did not considerably differ from the 1:1 relationship between the simulated distributions, corresponding to largest diameters being typically observed in individual tree detection. The larger the basal area, the more it was underestimated (cf. Vauhkonen and Mehtätalo 2015), while the systematic error in dominant height largely came from underestimating the number of trees. The realism of the assumptions made on the simulated distributions is further explored below.

\subsection{Simulated management practices}

Altogether seven different management alternatives based on different rules for harvested tree selection (Pukkala et al. 2015; Vauhkonen and Pukkala 2016) were simulated for each tree list. In addition to simulating the management alternatives for the different forest structures of the 40 stands, it was assumed for each stand that (1) it was located on one of three site fertility classes defined by Cajander (1926); either on Vaccinium myrtillus (mesic), Vaccinium vitis-idaea (sub-xeric), or Calluna (xeric) site

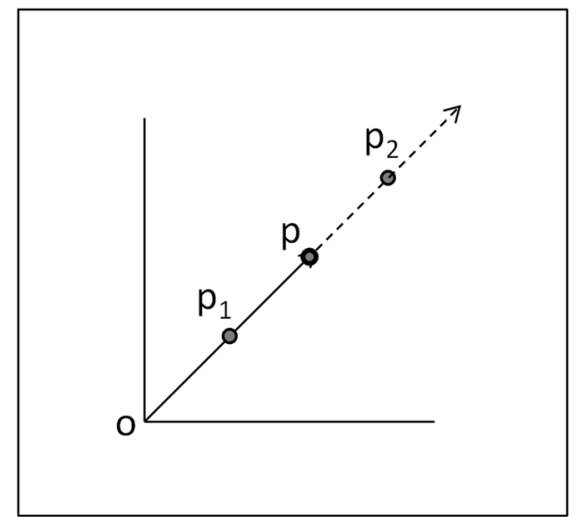

Fig. 1 The principle of linear interpolation applied to simulate distributions with varying accuracy. Left: the shape, scale, and frequency parameters of the distribution fitted with field data were considered as the origin (o). A vector per each parameter was projected from the origin towards the corresponding parameter values of distributions fitted to data interpreted by individual tree detection (p).

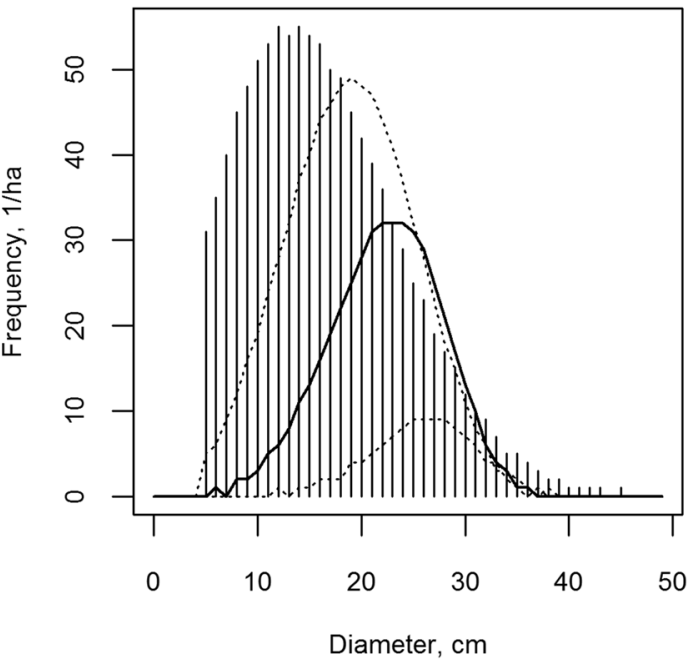

Two additional sets of parameters were obtained by means of linear interpolation: $p_{1}$ as the midpoint between $o$ and $p$ and $p_{2}$ as $p+$ the aforementioned midpoint. Right: an example of the obtained distributions. The solid lines represent the distributions o (vertical lines) and $\mathrm{p}$. The dashed lines having a better and a worse fit with the discretized reference distribution depict distributions $\mathrm{p}_{1}$ and $\mathrm{p}_{2}$, respectively 


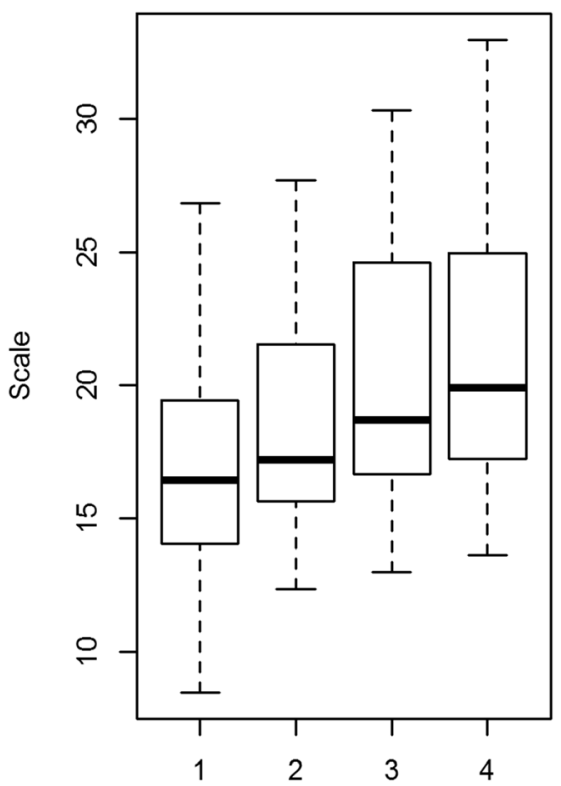

Distribution type

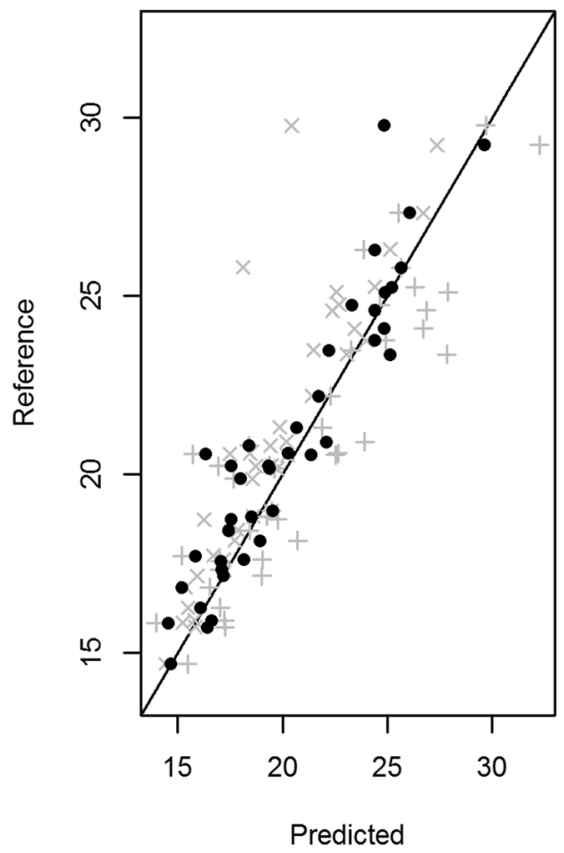

Fig. 2 Central differences between the simulated distributions. Top row, from left to right: the scale, shape, and frequency parameters of the distributions, shown separately for the reference (distribution type 1) and error-distorted distributions (2-4), of which distribution type 3 is fitted to the individual tree detection data and the other two are obtained by means of linear interpolation. Bottom row: predicted vs. reference

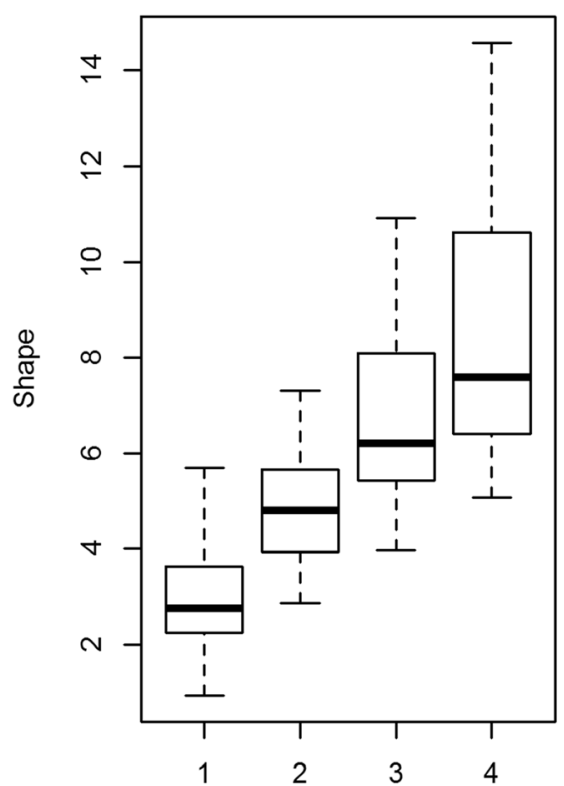

Distribution type

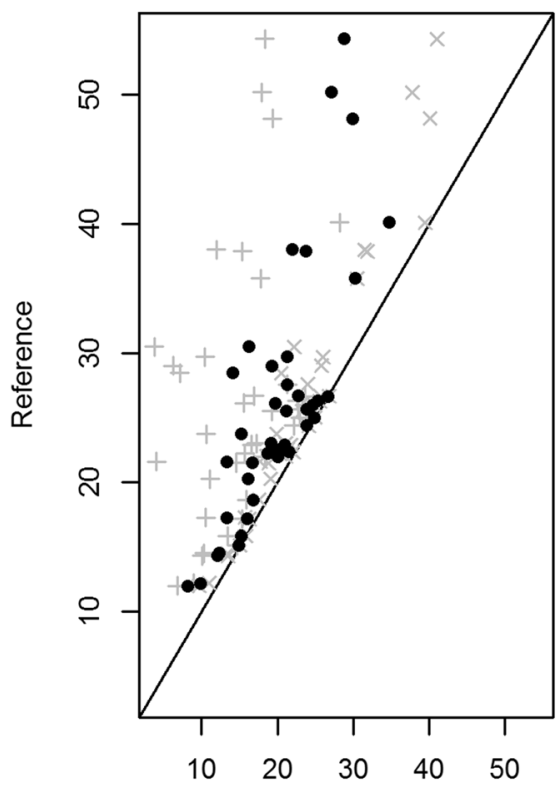

Predicted

basal area-weighted mean tree diameter (left; unit cm); basal area (middle; $\mathrm{m}^{2} / \mathrm{ha}$ ); and dominant height (right; $\mathrm{m}$ ). The filled circles indicate a comparison of the reference to the distributions fitted to the individual tree detection data, and crosses to those simulated by means of linear interpolation ( $\times$ and + correspond to the better and worse fit, respectively)

therefore produced different distributions of the harvested and remaining trees. Furthermore, the site type affected the productivity of the remaining tree stock and the interest rate determined the alternative rate of return, which

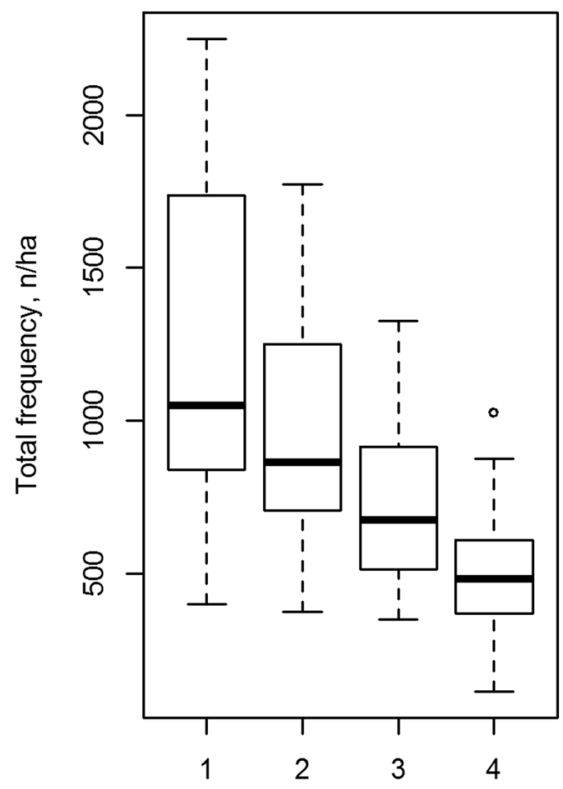

Distribution type

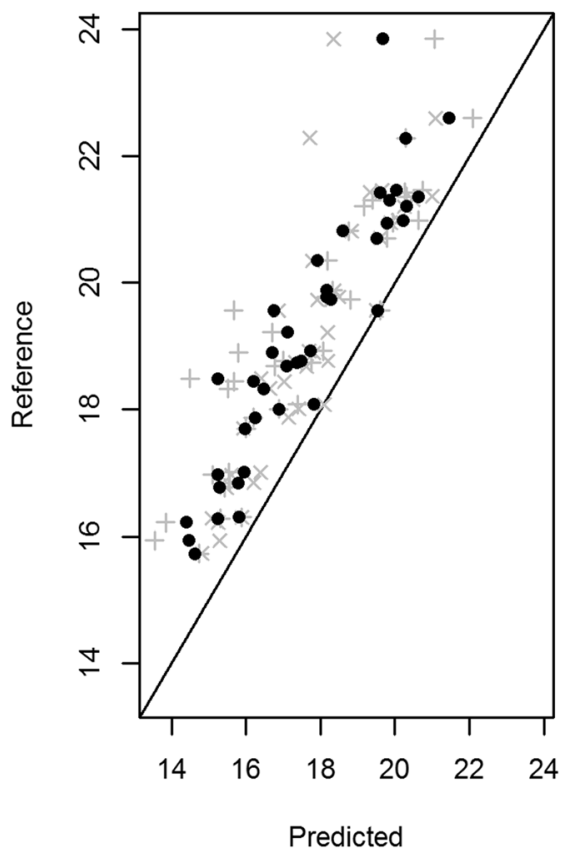

type; and (2) the decision-maker considered interest rates from 2 to 5\%. As illustrated using an example distribution in Fig. 3, the site fertility and interest rate affected tree selection rules in some harvesting alternatives and 


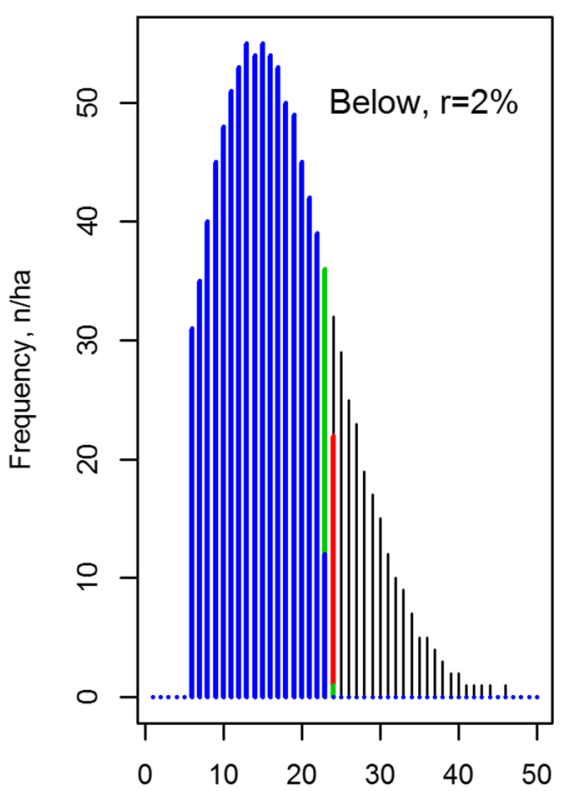

$\mathrm{DBH}, \mathrm{cm}$

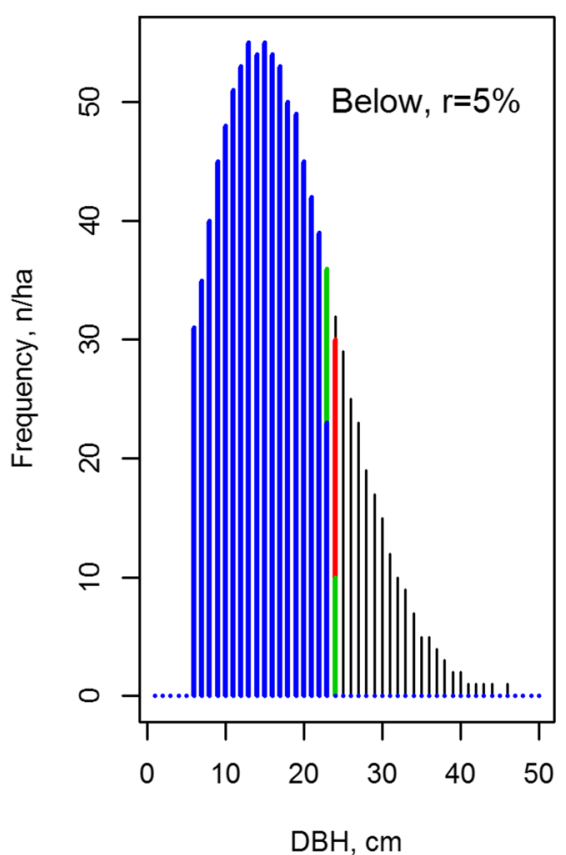

Fig. 3 Trees harvested vs. retained by different thinning alternatives applied to an example diameter distribution. Text in the sub-figures indicates the type of thinning and interest rate (r) applied. Blue color indicates trees that are removed from all tested site types. Green color indicates
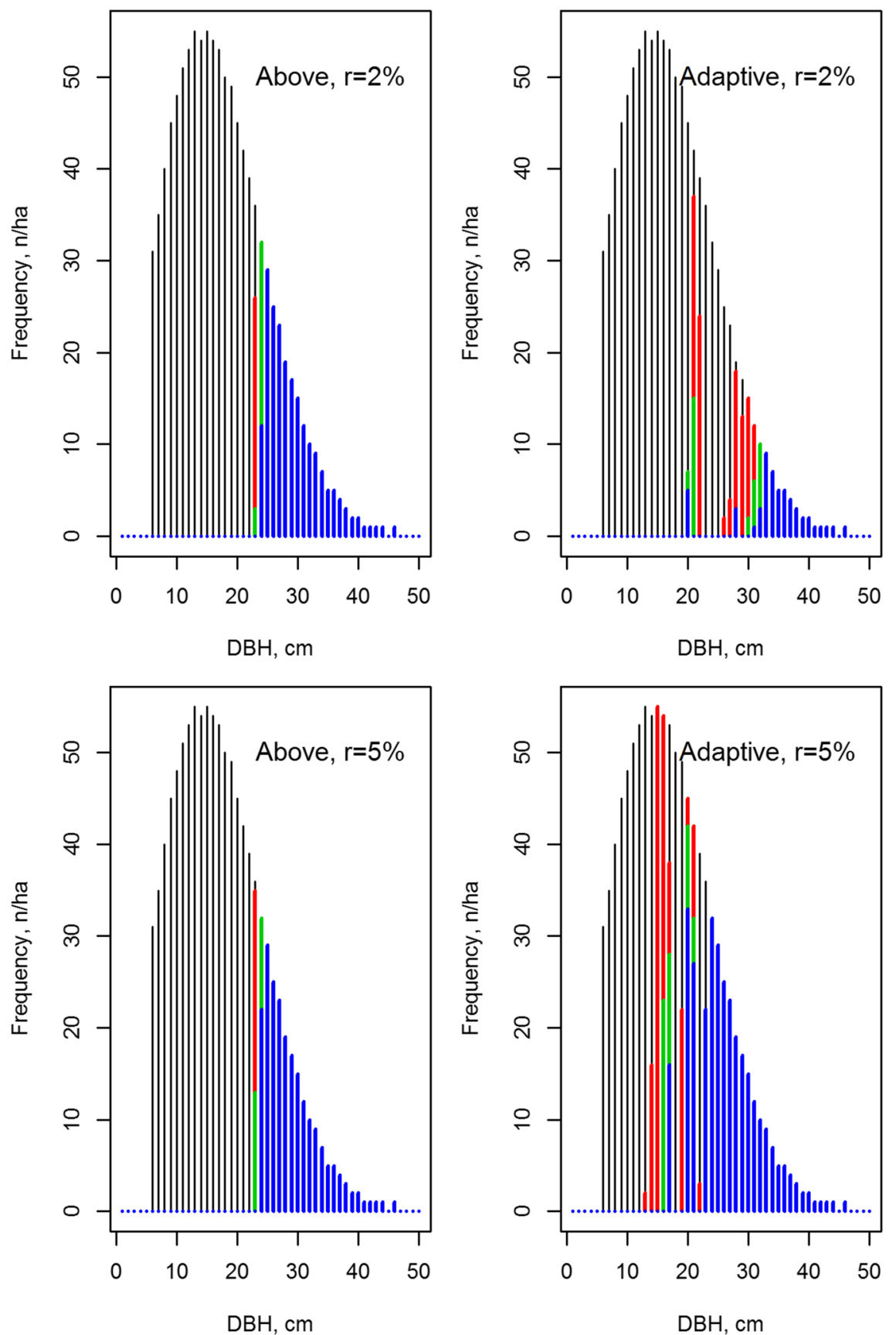

trees that are additionally removed, if the site fertility is Vaccinium vitisidaea or poorer. Red color indicates trees that are additionally removed from the poorest Calluna type

action later in the rotation depending on the properties of the tree stock and management objectives. In clear-cutting, the entire tree stock was final felled, leaving bare land to be artificially regenerated. In addition, a thinning from below and four alternative thinnings from above were simulated as follows: 


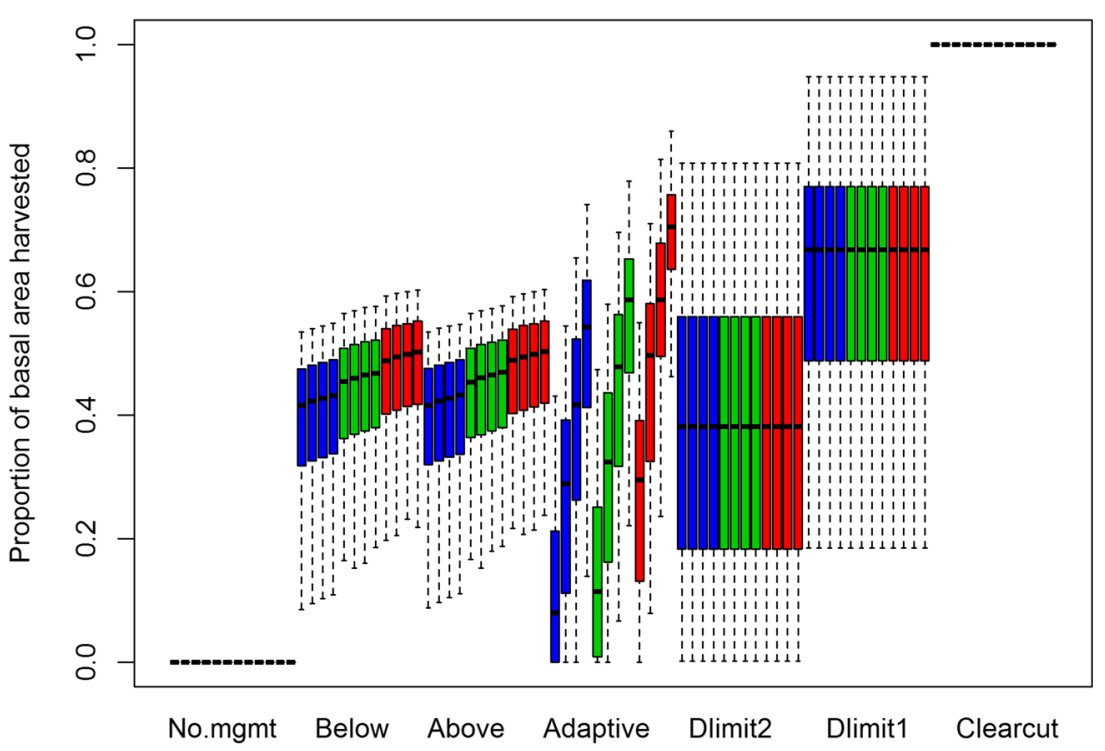

Fig. 4 Harvesting intensity (ratio of harvested to total basal area) in the different management alternatives, sorted in the figure according to approximately increasing mean intensity. A number of symbols corresponding to the number of site types $\times$ interest rates are drawn for each alternative. Blue, green, and red boxes correspond to Vaccinium myrtillus, Vaccinium vitis-idaea, and Calluna sites, and each site type is shown with interest rates that increase from 2 to $5 \%$ from left to right. The $x$-axis label indicates either no management (No.mgmt), clear-cutting (Clearcut), or the type of thinning, where Dlimit2 and Dlimit1 abbreviate diameter limit cutting producing at least two and at least one sawlog, respectively
- Thinning from below: an optimal residual basal area according to stand parameters including site fertility and interest rate was first predicted using equation 2 of Pukkala et al. (2015). Trees were removed starting from the smallest tree and in an ascending order according to the diameter, until the predicted residual basal area was met.

- Thinning from above was predicted according to a similar workflow as with the thinning from below, but the trees were removed starting from the largest tree and in a descending order according to the diameter.

- Adaptive thinning as defined by Vauhkonen and Pukkala (2016) was obtained as a result of an algorithm that changed tree status (harvest or retain) to produce a residual stand where each remaining tree had a value growth percent larger than or equal to the alternative rate of return (interest rate). The value growth prediction was based on growth models of Pukkala et al. (2009) and timber price and harvesting cost assumptions as presented below.

- Diameter limit cutting was simulated as a thinning from above a given diameter threshold, as motivated by Pukkala et al. (2015) that such an alternative could produce a feasible result based on simple tree selection criteria. Two alternative diameter limits were tested reasoning that it could be economically feasible to harvest all trees the bucking of which produced one or more saw logs. The threshold diameters of $18 \mathrm{~cm}$ or $22.5 \mathrm{~cm}$ were thus selected as the minimum diameters that yielded at least one or two sawlogs, respectively, according to predicted stem tapering and diameter-height relationship in these data.

The simulations of management alternatives and extraction of required statistics for comparisons were done by running an in-house Python 2.7 program that is available as an open source code (Vauhkonen 2019) and can be used to replicate the stand-specific simulations with input tree lists as produced according to the previous section. The program processes the tree lists for computing the aforementioned alternatives and reporting functions (see below). Using the diameter and height, the total stem and assortment volumes are based on taper curves (Laasasenaho 1982) and a simple method mimicking stem bucking into logs of saw timber and pulp wood. The computations are based on the same rules for allowable log lengths, minimum diameters, and price and cost assumptions as determined by Vauhkonen and Pukkala (2016) according to the specifications of roadsidetransactions carried out in the studied area.

\subsection{Evaluation}

The results of the treatments for the different forest structures were evaluated in terms of two criteria: (1) the present value of the harvested trees and (2) the soil expectation value (SEV) 
based on the remaining trees and the bare land. The immediate harvest income and future SEV were summed together and the management alternative that produced the largest total value was considered to be the optimal management for the stand in question. The dispersion of the selected alternatives was examined as a function of site fertility and interest rate for the reference diameters, and as a function of the basal area underestimation of the erroneous distributions assuming the different site types and interest rates.

The present value of the harvested wood $(€ /$ ha) was obtained as price $\times$ quantity of the obtained timber assortments minus estimated costs of cut-to-length-logging and roadside-transportation of the trees marked to be harvested. The costs were estimated by modeling the time expenditure of these operations as a function of harvesting type (clear-cutting vs. thinning) and the total removal using the models of Rummukainen et al. (1995). The time expenditure was multiplied by the unit cost assumed for operating a harvester and a forwarder in this area (cf. Vauhkonen and Pukkala 2016).

The SEV was the present value ( $€ /$ ha) of the costs and revenues resulting from timber production in the remaining tree stock (or bare land in the case of clear-cutting), when its management rotations are expected to continue in perpetuity. The SEV was obtained using a model that predicts the average value of a very high number of simulated rotations, in which the stand treatments were optimized for timber production with the given site fertility, growing stock, and operational environment (temperature, interest rates, and prices)-related parameters (Pukkala 2005). In the case of clear-cutting, the SEVs for the bare land were computed assuming that the regeneration was made preferring most suitable conifer species for each site type, being Norway spruce for Vaccinium myrtillus sites and Scots pine for less fertile sites.

\section{Results}

Even though the simulations were based on the simple Weibull form of the diameter distribution, multiple interesting results were produced, of which only a selection can be presented. Because of the aforementioned simple setup, it is not seen worthwhile to make a detailed stand-level examination. Instead, aggregated effects on the 40 simulated stands are examined. The effects of interest rate and site fertility on stand management decisions based on the reference distributions are first detailed (Section 3.1) to provide a benchmark for a comparison of similar decisions based on the erroneous distributions (Section 3.2).

\subsection{Implications of interest rate and site fertility on proposed management based on reference distributions}

Both the site fertility and interest rate clearly affected the optimal first decisions (Fig. 5, left column). Using an interest rate of $2 \%$, approximately half of the stands on the most fertile site did not receive an immediate management action, this proportion reducing according to a decreasing site fertility. If immediate management was suggested, the most frequent management action proposed using the $2 \%$ interest rate was diameter limit cutting of all stems that produced at least two sawlogs. Using an interest rate of $3 \%$, most of the stands were proposed to be harvested and this proportion increased according to a decreasing site fertility. The most frequent management action with interest rates $3-5 \%$ was diameter limit cutting of all stems that produced at least one sawlog (the most intensive thinning alternative, cf. Fig. 4). Other management alternatives were employed single or only a few times with interest rates $4-5 \%$ and excluding the most fertile site type, in which more variety was observed. Clear-cutting was the only alternative that never became selected. The effects described above are logical and similar to those presented elsewhere. With low interest rates, the future SEV based on the current tree stock was often higher than immediate harvest income + future SEV of any harvesting alternative, resulting to the no-management option. The income obtained from management practices applied later during the rotation resulted to higher net present values than immediate management specifically assuming low interest rates. With increasing interest rate, obtaining income earlier in the rotation became more important and it increased the proportion of forests harvested immediately. This happened more frequently the coarser the site, as future SEVs became lower in poorer sites due to lesser growth.

It is worthwhile to note that especially using high interest rates, the management alternatives that produced the highest sum (immediate harvest income + future SEV) frequently required thinning the stands either (1) to a residual basal area that was below the legislative minimum (about $8 \mathrm{~m}^{2} / \mathrm{ha}$ in the studied area) or (2) so lightly that the operation was not profitable. Occurrences of (1) were most typical to the diameter limit cutting alternative that did not consider the residual basal area and (2) also for some other thinning alternatives, if the stand was already initially very sparsely populated. The results were therefore alternatively produced by introducing legality and profitability conditions, according to which the postthinning basal area had to exceed the legal limit and the net income had to be positive, regardless of the effect these choices had on immediate harvest income + future SEV. The alternatives not meeting these conditions were simply ignored. The resulting effects (Fig. 6) can be compared with the 


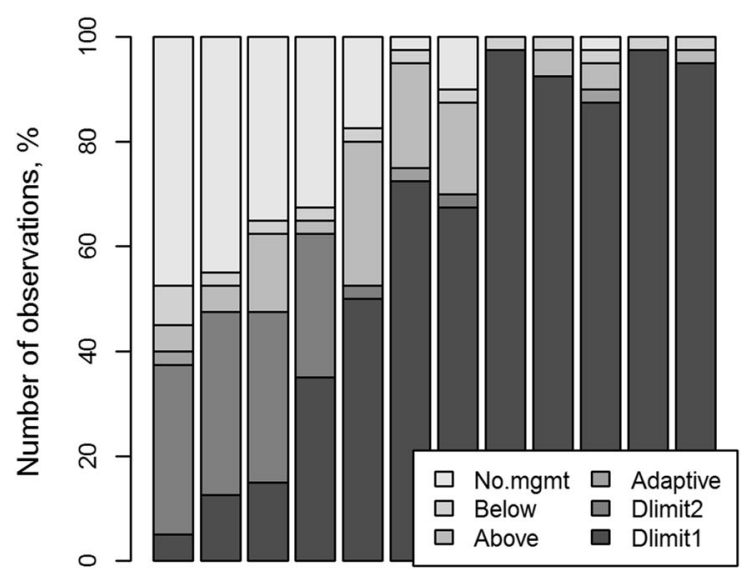

$\begin{array}{lllllllllllllll}\text { MT } & \text { VT } & \text { CT } & \text { MT } & \text { VT } & \text { CT } & \text { MT } & \text { VT } & \text { CT } & \text { MT } & \text { VT } & \text { CT }\end{array}$ $r=2 \% \quad r=3 \% \quad r=4 \% \quad r=5 \%$
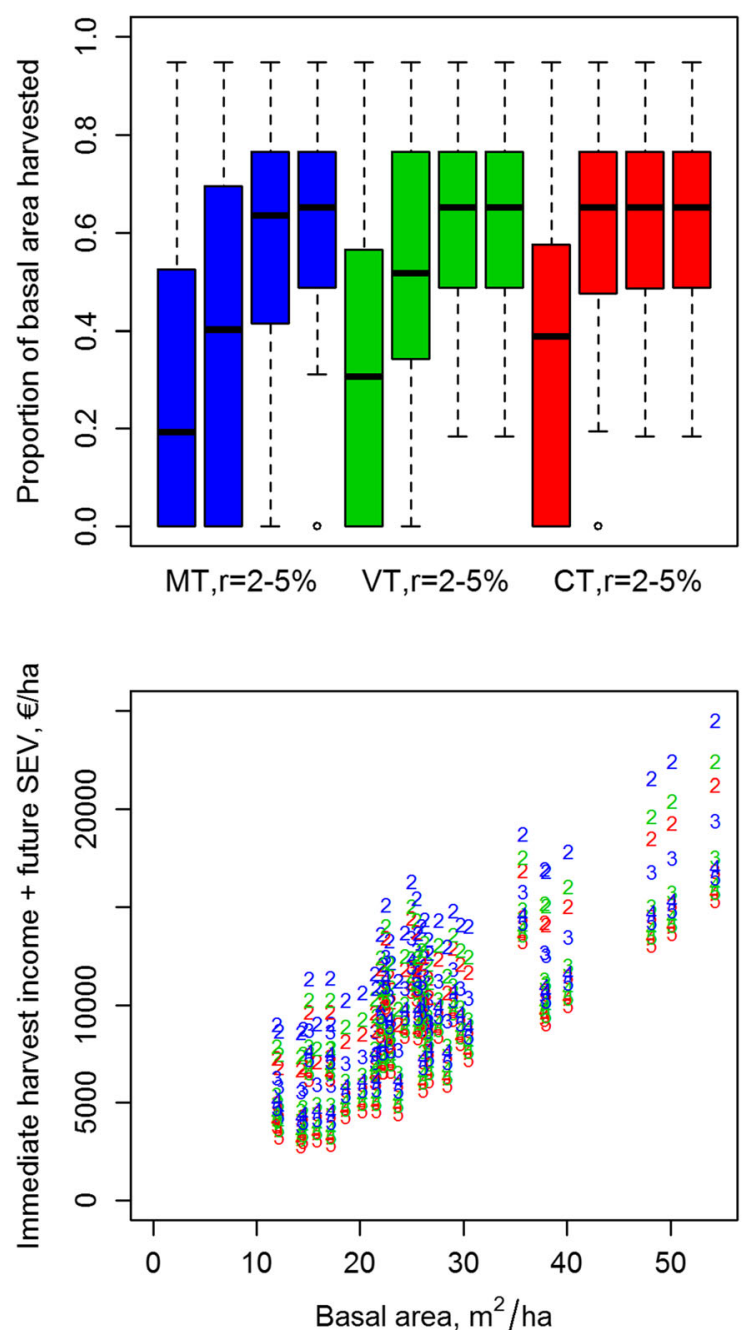

Fig. 5 Distribution of management alternatives that produced best outcome (top row) and corresponding harvesting intensity (middle row) according to immediate harvest income + future SEV (bottom row) based on the reference (left column) and typical, error-distorted distribution. In the top row, the legend indicates either no management (No.mgmt) or the type of thinning, where Dlimit2 and Dlimit1 abbreviate diameter limit

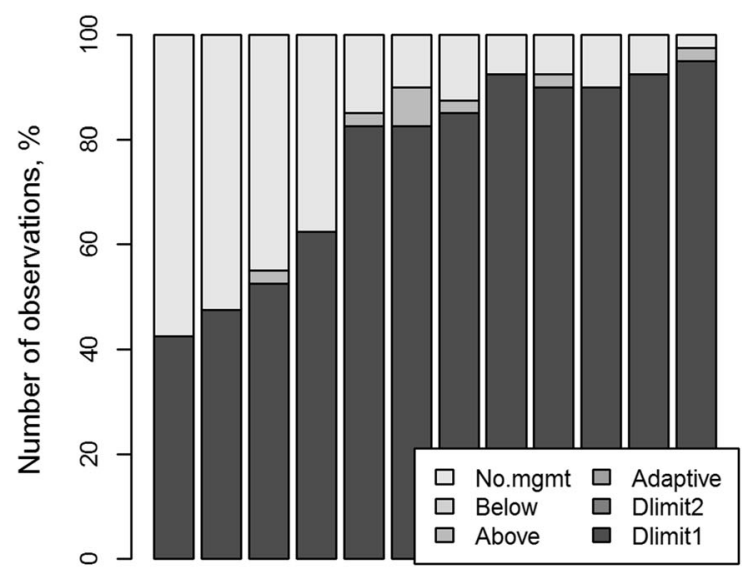

$\begin{array}{llllllllllll}\text { MT } & \text { VT } & \text { CT } & \text { MT } & \text { VT } & \text { CT } & \text { MT } & \text { VT } & \text { CT } & \text { MT } & \text { VT } & \text { CT }\end{array}$ $r=2 \% \quad r=3 \% \quad r=4 \% \quad r=5 \%$
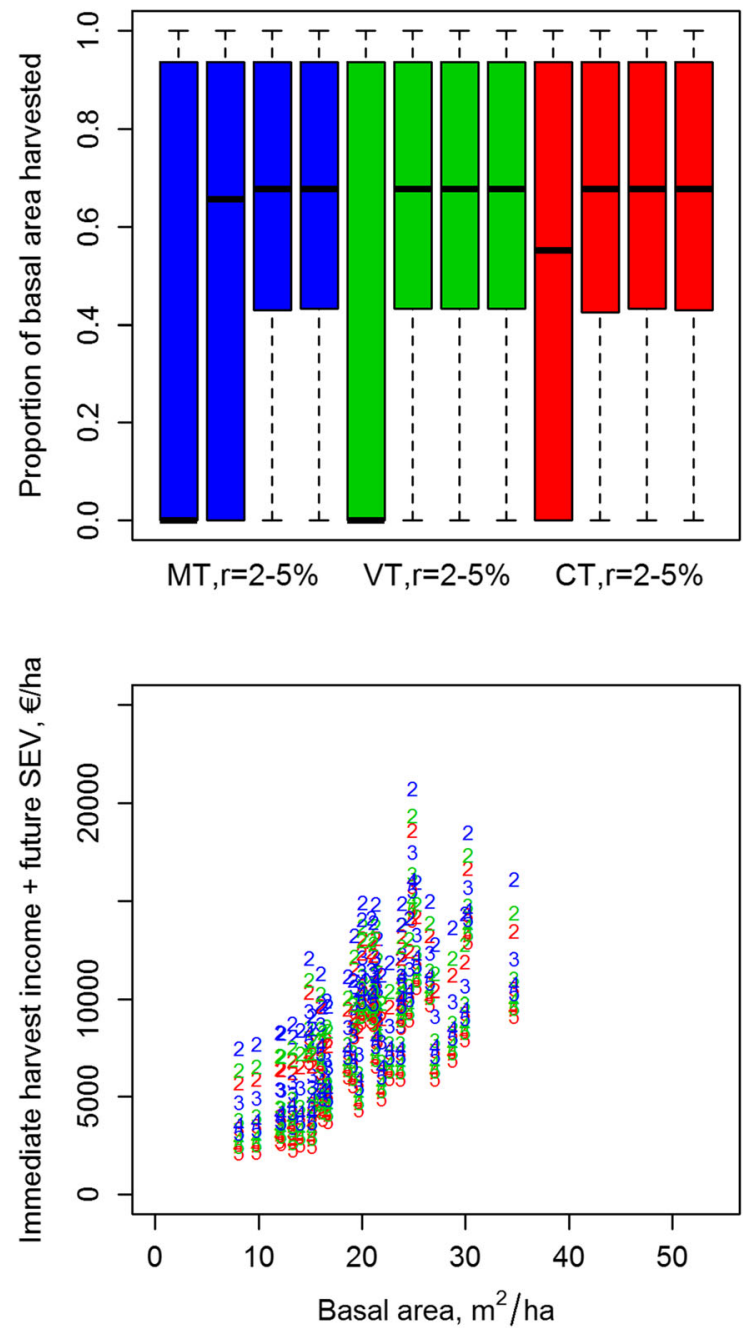

cutting producing at least two and at least one sawlog, respectively. The clear-cutting alternative is not shown in the legend as it never became selected. Blue, green, and red symbols correspond to Vaccinium myrtillus (MT), Vaccinium vitis-idaea (VT), and Calluna (CT) site types. In the bottom row, interest rates (r) $2-5 \%$ are shown by the corresponding number 

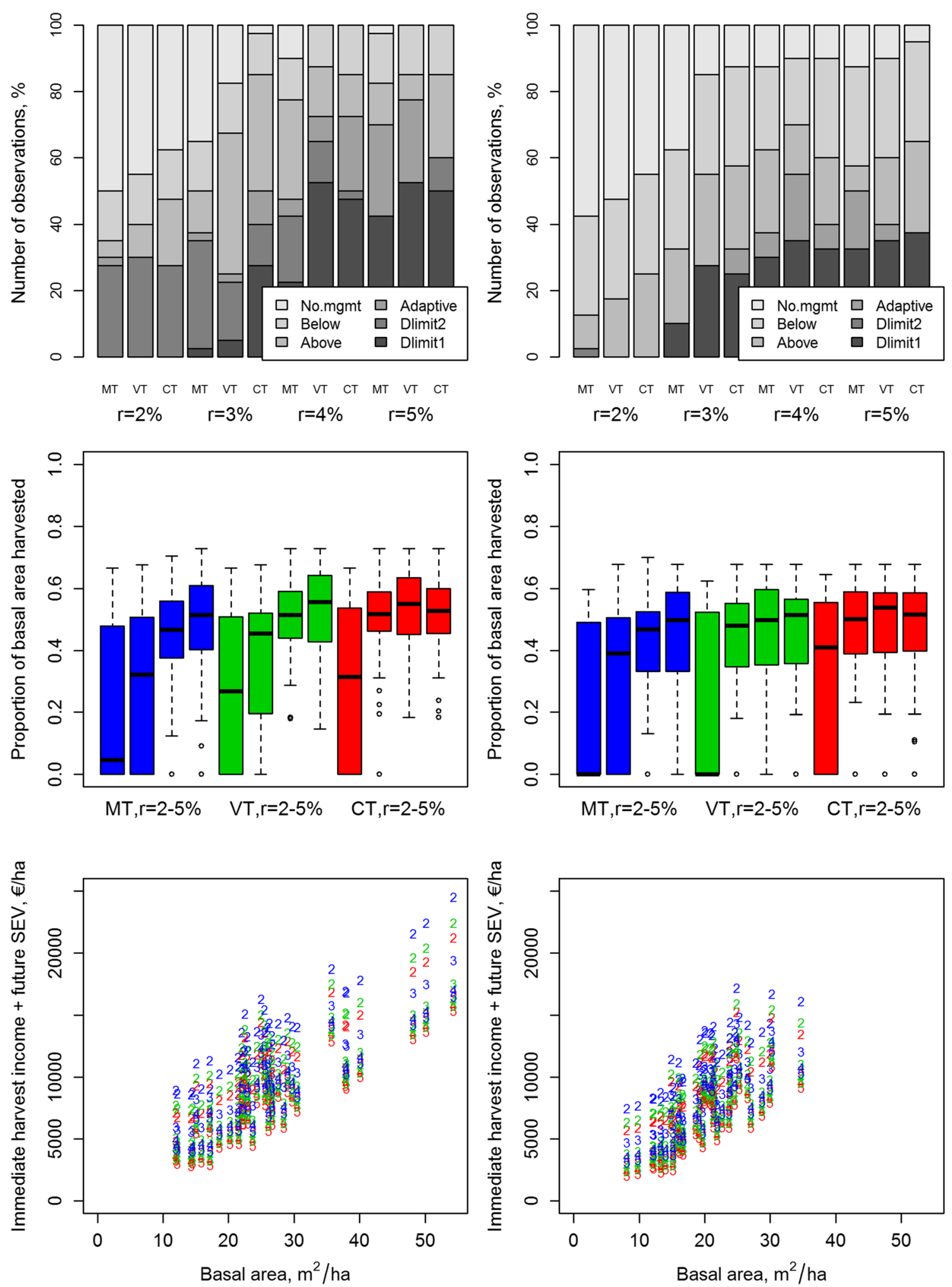

Fig. 6 Results shown in Fig. 5 reproduced considering thinning alternatives that produced a post-harvest basal area exceeding the legal limit $\left(8 \mathrm{~m}^{2} / \mathrm{ha}\right)$ and positive net income from the harvesting operation when selecting the best alternative according to immediate harvest income + future SEV

unconstrained results (especially, the left column of Fig. 5 in the case of the reference distributions). Introducing these conditions notably increased the variation between management alternatives selected and, overall, reduced average 
harvesting intensities. The choice between no management and management was approximately similar as above, but diameter limit cutting was much less employed, because of difficulties to meet the conditions. Interestingly, the use of adaptive thinning became more frequent according to increasing interest rate; however, this alternative was replaced by thinning from above with specified residual basal area requirement, more frequently the lower the site fertility. An almost fixed proportion (six stands) was thinned from below independently of interest rate and site type. Clear-cutting was never employed. Introducing these conditions reduced the sum of immediate harvest income and future SEV slightly (cf. bottom rows of Figs. 5 and 6).

\subsection{Implications of erroneous diameter distributions}

The right-hand columns of Figs. 5 and 6 present the corresponding results based on data from the typical, errordistorted distribution. When no legality and profitability constraints were applied (Fig. 5), the set of management alternatives considered included less distinct management alternatives and the resulting harvesting intensities were considerably averaged. The choice between no management and management did not change remarkably, but the diameter limit cutting of trees that produced at least one sawlog (the most intensive thinning alternative) was almost only management alternative employed. When the legality and profitability conditions were applied on the erroneous data (Fig. 6), the diameter limit cutting that produced two logs was not employed and the total proportion of stands for diameter limit cutting was considerably reduced. An almost fixed proportion (twelve stands, i.e., twice the amount of reference distributions) was suggested for thinning from below independently of interest rate and site type. The other two types of distributions simulated with varying data accuracy assumptions are not shown, but they can be described to have suffered less and more of the error types above according to less and more severe displacement, respectively, compared with the reference distribution.

The reason for the behavior described above can be better understood by examining the immediate harvest income and future SEV components separately, as done in Figs. 7 and 8. Although the sum of immediate harvesting income + future SEV is typically underestimated as illustrated in the bottom rows of Figs. 5 and 6 , it is seemingly done the same way between the management alternatives and without a considerable effect of data accuracy (the right-hand column of Fig. 7). However, these components are differently estimated and either the immediate income or future SEV is overweighted in the sum to a degree that varies between the management alternatives.
When the immediate harvest income and future SEV were estimated independently, as in the case of clear-cutting and no management, respectively, the underestimation of the growing stock had a linear effect on these values (Fig. 8a). In all other management alternatives, these values depended on both the harvested and retained tree stock and, consequently, estimation of both the stocks that was done in varying accuracy between the management alternatives (Fig. 8). For instance, when the harvestable tree size and, consequently, the immediate harvesting income by the thinning from below alternative were overestimated as shown in Figs. 7 and 8, this management alternative became selected as optimal management twice more often than in the error-free data (compare the leftand right-hand side of Fig. 6).

Following the management recommendations based on erroneous inventory data could result to losses that can be approximated as the difference between the selected and optimal alternative according to the reference data. The use of the erroneous data did not cause such losses in altogether $71 \%$ of observations of the present data; i.e., the management decision was the same even with lower quality data, and not much affected by data quality. However, in cases where losses occurred, the losses attributed to $2.1 \%$ of total predicted harvest income + future SEV, on average, and about $17 \%$ at maximum, compared with the optimal choice with the reference data. Figure 9 further illustrates the distribution of relative losses $>0 € /$ ha.

Based on simulations with the reference data, it was known that certain alternatives never became selected with certain combinations of site type and interest rate (cf. Fig. 5). Prohibiting simulations of these alternatives also with the predicted data reduced the mean and maximum relative losses to $1.8 \%$ and about $13 \%$, respectively. Although the loss reduction due to introducing this condition is minor, on average, Fig. 9 indicates that the reduction was most often focused on stands that had the highest relative losses. Other types of similar criteria could possibly be derived by considering the feasibility of the alternatives simulated on remotely sensed data according to general knowledge of the simulation logic or decision rules developed in external data.

\section{Discussion}

Errors in diameter distributions distorted the predictions of both the harvest income and future SEV differently between simulated alternatives, which changed the frequencies the alternatives were considered as optimal management compared with the use of the error-free reference distributions. This bias could not be expected, if only the sums of immediate harvest income and future SEV were compared. These findings are 

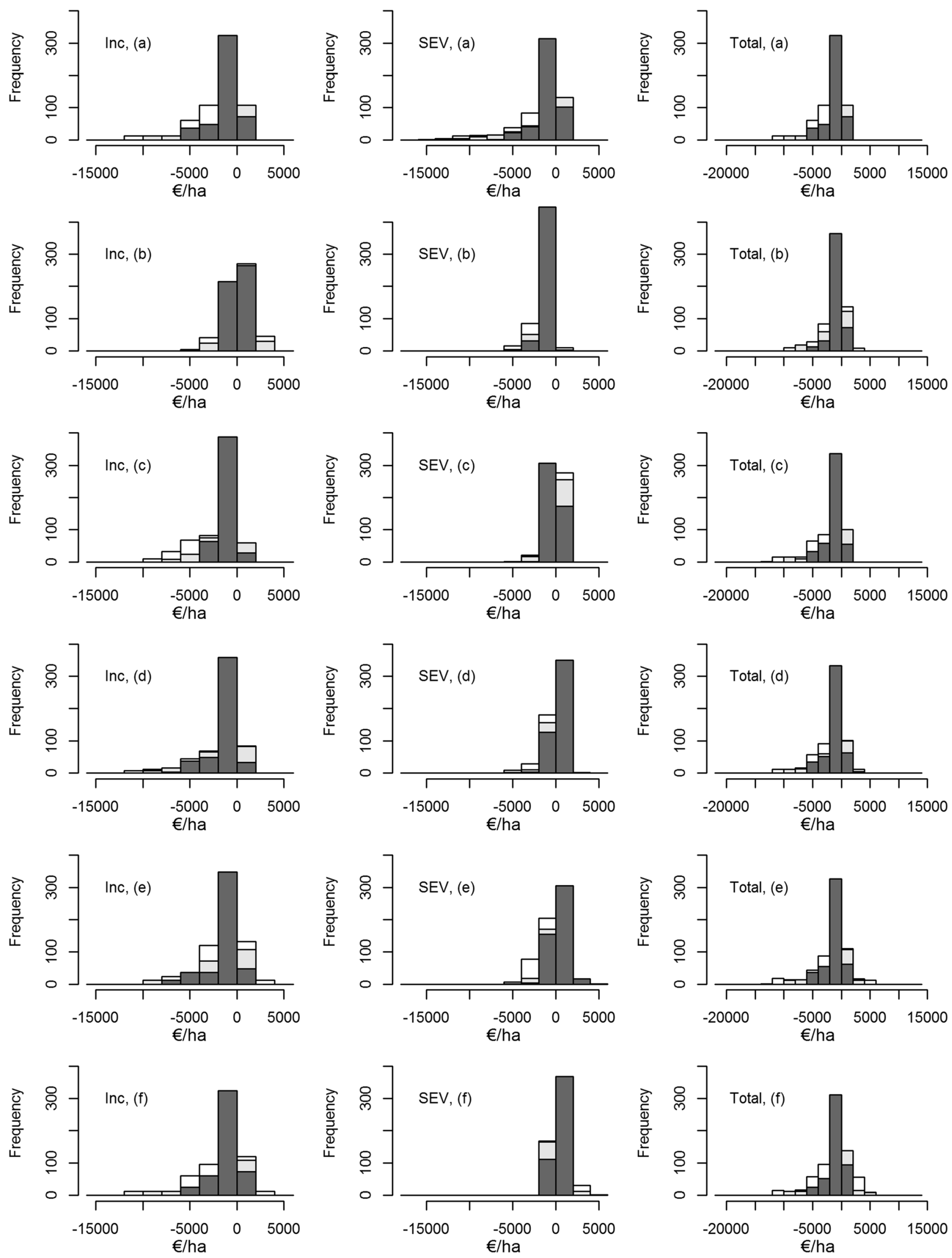
Fig. 7 Differences from reference to error-distorted distributions in immediate harvest income ("Inc"; left column), future SEV ("SEV"; middle), and the sum of these components ("Total"; right), when predicted based on trees harvested vs. retained according to different management alternatives. The top row (a) shows the immediate income due to clearcutting, the SEV of no management, and the clear-cutting value + the bare land expectation value, whereas the other rows show these values from single management alternative at a time, being thinning from below (b), thinning from above (c), adaptive thinning (d), and diameter limit cutting producing at least two (e) or at least one sawlog (f). Dark gray filling depicts the typical, error-distorted distribution, while effects due to data accuracy simulated by means of linear interpolation are illustrated using other shades of gray

further discussed from the points of view of realism of the assumptions made, differences between the management alternatives, and practical considerations that should be made due to these results.

When designing the simulations, the tree detection was assumed to be the dominating error source (cf. Vastaranta et al. 2011) and the theoretical Weibull distribution forms were assumed to be adequate in describing the variations of the diameter distributions. As reasoned by Čugunovs et al. (2017), for example, the values of the shape and scale parameters of the two-parameter Weibull distributions can quantify differences between forest structures. When the parameters of both the reference and errordistorted distributions were based on the Weibull distributions studied by Vauhkonen and Mehtätalo (2015), the present results should correctly reflect the performance of the individual tree detection and consequent error propagation in similar forest structures (pure Scots pine stands in Eastern Finland). The distributions simulated for the lower performance by extrapolating are admittedly very poor for some plots and unlikely to be realistic. However, also these figures were useful for assessing the degree of error propagation to decisions caused by severely incorrect inventory data vs. other factors. Interested readers can change assumptions related to input data and, for instance, select the evaluation criteria differently, because the codes producing the management simulations are given as supplementary data.

Many additional sources of errors affecting the inventory data could be considered. For instance, the ability to predict tree height was not assumed to vary between distributions. However, different data sources could underestimate the number of trees similarly but differ in terms of predicting tree height or other attributes. If pure, singlespecies stands were not assumed, predicting tree species incorrectly could produce significant degrees of errors, because the assortments of different species have considerably different properties and therefore different prices. Also, although site type was considered in the analyses, it was assumed not to include errors. It is usually assumed to be accurate when obtained from existing inventory data (Maltamo and Packalen 2014) and errors in site type were recently found to cause much less severe economic losses than those related to tree species proportions (Haara et al. 2019). Simulations of errors in all attributes would require a considerably more complex simulation approach. For instance, if tree species was interpreted incorrectly, it could affect the features used to predict allometric relationships and depend on trees surrounding the tree in question, for which reason the simulations should consider interactions between species and other attributes.

Simulating only the first management action and not including a long chain of simulation and optimization steps were expected to isolate the effects of input data from those related to other steps of the modeling chain. Also, the latest studies by Pukkala (2018) indicate that instructing any-aged forest management can be done quasi-optimally by modeling the immediate need for silvicultural treatment. The first management decision largely affects the production potential also further in the rotation, but because the entire rotations were not simulated, the management actions were consequently not optimized for longer time spans. Instead, the best management alternatives were selected according to immediate harvesting income + the predicted SEV of future rotations simulated to continue in perpetuity, starting from either the residual stand or bare land. Never selecting clear-cutting as an optimal management action may result from predicted bare land SEVs being very small (the smaller, the higher the interest rate). Yet, this is a logical outcome, because an artificial regeneration after a clear-cut introduces large costs at the beginning of a rotation and makes alternatives utilizing natural regeneration more profitable (e.g., Pukkala 2016a; Pukkala 2018).

The future SEVs were predicted by models of Pukkala (2005) that are usually applied to cover net income from later rotation after first few planning steps simulated in more detail (e.g., Pukkala et al. 2014a; Pukkala 2016a). Although applying the model immediately after the first management decision should not affect the comparisons, a few remarks on the SEVs predicted for the residual stands should be made. The model fitting data of Pukkala (2005) might not cover post-harvest stand structures like those resulting from unconstrained diameter limit cuttings of this study. The accuracy of the SEV predictions for those alternatives could thus be questioned, for which reason the focus should be on the data simulated by applying the legality and profitability conditions. Additionally, 

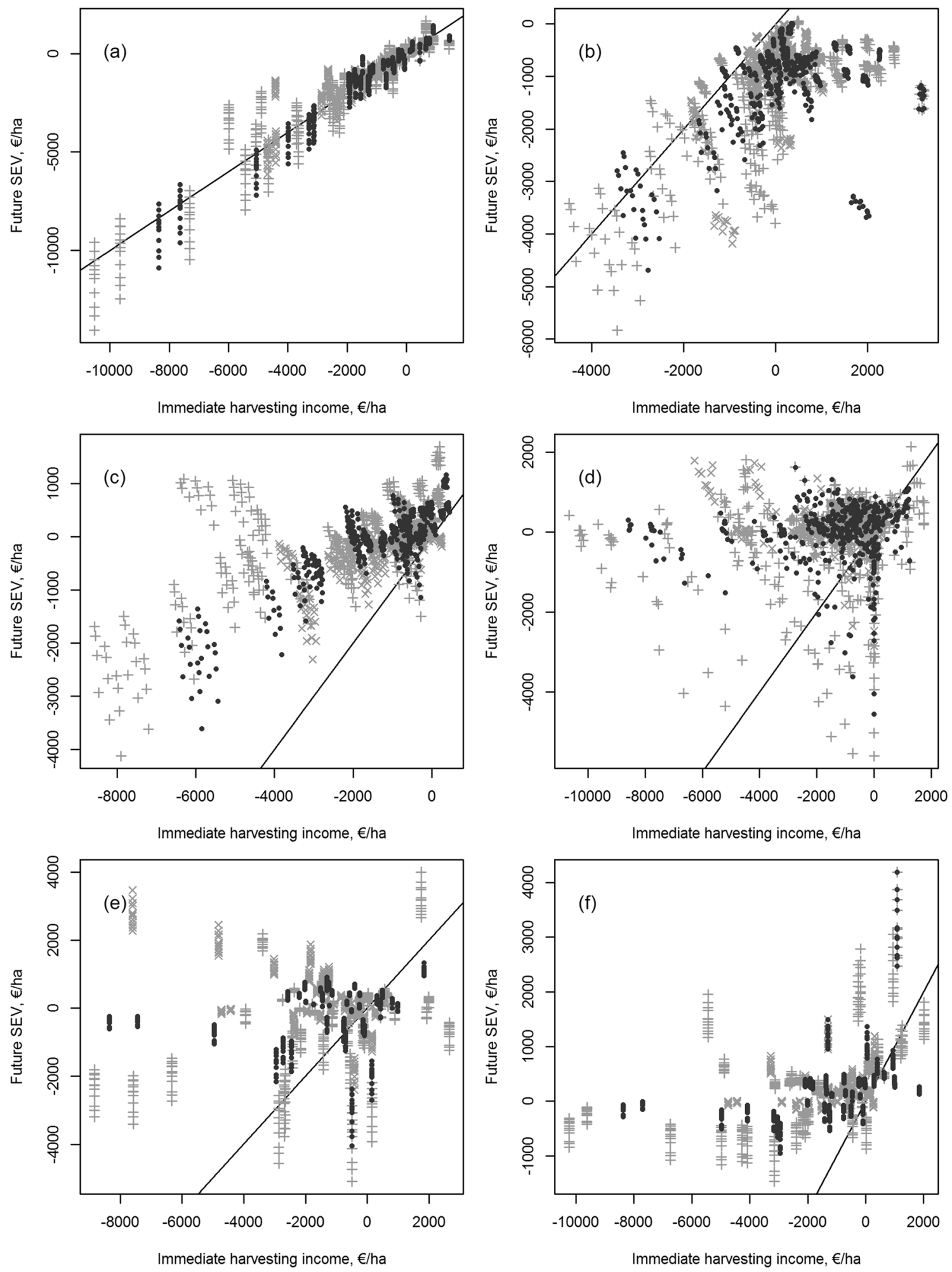

Fig. 8 Differences from reference to error-distorted distributions in immediate harvest income ( $x$-axes) vs. future SEV ( $y$-axes). For the interpretation of sub-figure labels a-f, see the caption of Fig. 7. The filled circles indicate a comparison of the reference to the distributions fitted to the individual tree detection data, and crosses to those

simulated by means of linear interpolation $(\times$ and + correspond to the better and worse fit, respectively). All considered site types and interest rates are shown, but differentiating among them is not seen necessary 


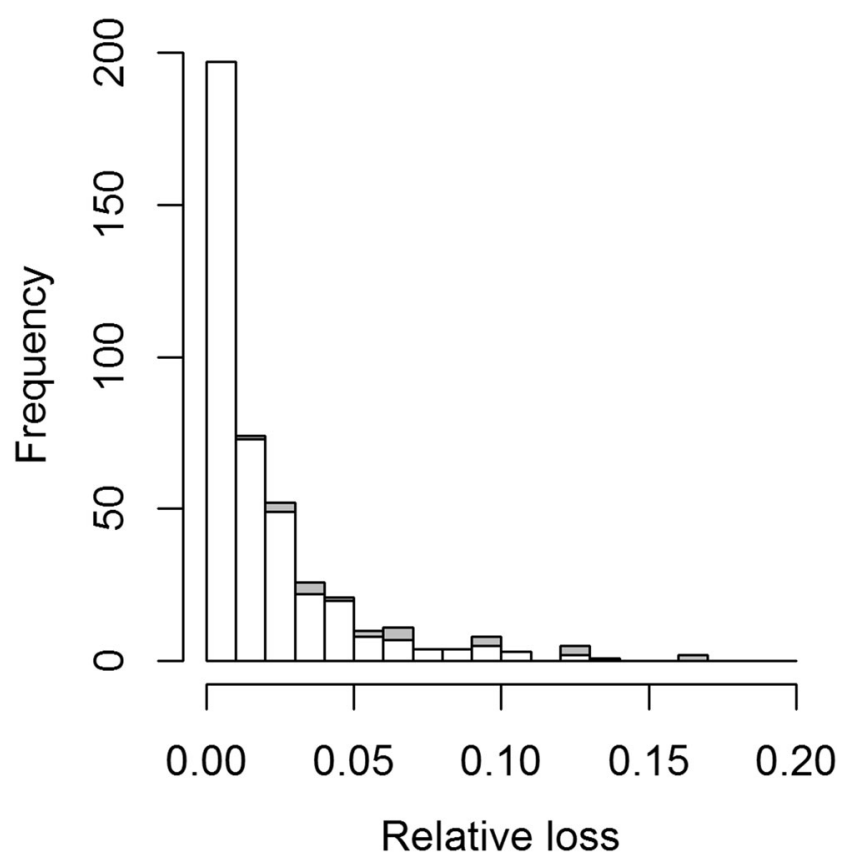

Fig. 9 Frequency of relative losses (difference between the selected and optimal alternative/total immediate harvest income and future SEV of the optimal alternative) in the studied data. Proportions of bars colored by gray indicate losses that can be avoided by prohibiting simulations of such management alternatives that were never selected based on management instructions simulated with the reference data

although the simulations of Pukkala (2005) used stumpage prices excluding harvesting and transportation costs, the models were applied using roadside prices. The immediate harvesting income was computed by deducting estimated costs from the timber value, and because the proportion of costs depended on the size and total amount of the harvested trees, it was specific to each stand and each management alternative, and reconciling the prices between simulation steps was not straightforward. When the stumpage and roadside prices mainly differ for pulpwood, the discovered inconsistency was not expected to be remarkable. A separate test indicated that accounting for this difference would drop the absolute values of the future SEV predictions of all residual stands by a factor, which however was smaller than the difference to the bare land SEV that would make the clear-cutting option feasible (cf. previous paragraph).

The SEV prediction models by Pukkala (2005) do not assume a certain (fixed) management regime for the future. If the purpose was to instruct a continuation of uneven-aged forestry repeatedly for a long time, even more severe implications due to inventory errors than presented here could be obtained. That is because errors in individual tree detection may present the forests as adequately sparse and exaggerate the potential for natural regeneration, as forestry dynamics models fitted with error-free data predict more in-growth for sparse stands (Eerikäinen et al. 2007). Incorrect stand density will also affect natural mortality and growth and yield predictions (cf. Kangas 1998). If an optimization was included, systematic errors in data would show as an optimization bias: in addition to maximizing objective function, also the overestimate in the target variables would be maximized, giving more emphases to management alternatives with the highest systematic errors. Yet, in an operational reality, the planning of long-term management would be based on projections re-computed occasionally.

Based on current results, it was important to consider the operational environment in which the inventory was operated. Here, legal constraints, profitability of harvesting, site type, and interest rate jointly affected the selection of a feasible management. The mechanism by which the interest rate affected the results was via different management intensity applied to stands with different structures. In other studies, the interest rate has been found to affect the optimal data accuracy (Kangas et al. 2015) depending on risk aversion of a decision-maker (Eyvindson et al. 2017). Because of interactions between inventory data and external factors that constrain the feasible set of management actions, it is recommended not to separate but to integrate the inventory and planning systems for well-informed decisions. Except for taking this nature of information into account, an example of how to utilize knowledge from both planning and inventory systems is given in the last paragraph of Section 3.2. Taken together with experiences obtained here, the suggestion by Pascual et al. (2013) to more tightly integrate expert opinion in remote sensing studies is advisable, and even more intuitive in studies considering decision support based on functions involving expert judgment (see also Kangas et al. 2018b).

It seems to be well-reasoned to simulate only simple management actions, when data accuracy is in question. In the present case, a few alternatives corresponded to thinning from above but based on different selections of harvested and retained trees. The difference between these alternatives in terms of immediate harvesting profit $+\mathrm{fu}-$ ture SEV was however much smaller compared with thinning from below and clear-cutting. It thus appears reasonable to differentiate between these main harvesting types in the tactical planning and leave more delicate decisions to operational planning. It was initially assumed that diameter limit cutting could be a feasible simulation method under low data accuracy, because it did not involve many 
decision variables. In contrast, simulating diameter limit cutting on erroneous tree data considerably distorted estimates of both harvested trees and the residual stand. The simulations did not consider realistic harvest implementations; in practice, however, trees cannot be removed sequentially according to the diameter due to requirements to open trails for the harvesting machinery, for example, which can affect the results.

One could attempt to improve the quality of the diameter distribution predictions. However, although it is acknowledged that many methods exist for compensating for the stem number left undetected, not as many methods extend the correction to cover frequencies of the diameter distribution (but see Vauhkonen and Mehtätalo 2015; Kansanen et al. 2019). On the other hand, it could be possible to accept the errors and not to aim for a high overall accuracy, but to develop prediction methods to optimally respond to management questions at hand, as also suggested by Mauro Gutiérrez et al. (2019). In that case, a forest manager primarily looking for stands most in need of treatment could desire different proportions of stands estimated accurately than one seeking for accurate total growing stock estimation. Individual tree detection results have been combined with diameter distributions predicted using area-based methods that optimize the selection of a cutting point between two sources of distributions (Xu et al. 2014; Hou et al. 2016). Although not tested for forest planning computations, it could be more feasible than improving the predictions to employ different cutting points according to the needs of forest managers according to the reasoning above.

There has been a growing interest to use spatial optimization to generate dynamic treatment stands from small inventory units (Pukkala et al. 2014b; Pascual Arranz 2018). The results above could be timely, because similar methods are also likely to be applied at the level of individual tree segments. Earlier tree-level harvest planning models (Pukkala and Miina 1998; Pukkala et al. 2015; Vauhkonen and Pukkala 2016) can be run on spatially explicit tree data produced by remote sensing that is already done by Wing et al. (2019). Making spatially explicit selection of trees harvested and retained can produce feasible results in sparse stands and among discernible trees (as in Wing et al. 2019). Based on the results above, considerable challenges are foreseen, if the tree-level planning requires information also on below-dominant trees and that information is obtained from the remotely sensed data. In that case, a forest manager should recognize that a tree or tree group might or might not exist in the data and it might be of different size and species than predicted. If management objectives require optimizing the composition of understory trees, such methods that allow associating the trees with probabilities that they exist and are of the indicated species and size should be used. If these projections are extended longer in the future, also the uncertainties should be projected, which is seen as challenging.

\section{Conclusion}

Making tree-level management decisions is motivated as treelevel forest inventory data become increasingly available. However, airborne inventories carried out tree-by-tree typically include systematic errors, which can propagate subsequent management decisions. According to simulations of underdetection focused on the smallest trees, errors in diameter distributions affected the predicted, immediate harvest profits and future expectation values differently between the simulated alternatives and depending on site type and interest rate assumptions. As a result, different harvesting types and management intensities were proposed compared with the use of the error-free reference distributions. Management decisions based on the erroneous information caused losses of $0-17 \%$ of the total immediate and future income. These effects might not have been discovered, if the results were validated for inventory totals instead of separately considering the immediate and future income and losses produced by the erroneous decisions. It is recommended not to separate but to integrate the inventory and planning systems for well-informed decisions.

Acknowledgments I would like to thank Professor Annika Kangas for providing comments to an early manuscript version.

Funding Information Open access funding provided by Natural Resources Institute Finland (LUKE).

Data availability The tree lists analyzed can be regenerated according to Annexes 1 and 2 (Table 1) and used as inputs for a program available in the Zenodo repository (Vauhkonen 2019), https://doi.org/10.5281/ zenodo. 2645064 .

\section{Compliance with ethical standards}

Conflict of interest The authors declare that they have no conflict of interest.

\section{Annex 1}

R-code prepare data.R generates the input tree lists of the study according to Section 2.1 using the distribution parameters provided as Annex 2 Table 1 
\#prepare_data.R

\# Assume that input distribution parameters (table Annex 2) are in dataframe called \# data. The different parameters are picked up and re-arranged to new data frames: $\mathrm{n}<-$ data $[, \mathrm{c}(1: 3)]$ \# Stem number

shape <- data $[, \mathrm{c}(1,4,5)]$ \# Weibull shape

scale <- data $[, \mathrm{c}(1,6,7)]$ \# Weibull scale

\# The code below prepares separate files for tree and plot data. The plot data are only the plot id's added with site type and temperature sum. An example of that information is given below: (CT = Calluna site and 1100 is temp.sum in degree days) plotrow <- "CT,1100"

\# Fit height curve with lmfor (its spati dataset) - note this library is needed! lmfor.available <- require (lmfor)

if (lmfor.available) \{

data (spati)

naslund.model <- nls (h HDnaslund (d,a,b), data=spati, start=list $(a=1, b=1)$ ) \}

naslund.a $<-$ coef (naslund.model) [1]; naslund.b <- coef (naslund.model) [2]

\# A helpful function used later in the processing to format the tree list helpf $<-$ function(i) \{

paste (i[1], which (i[2]==unique (treelist [,2])), i[3], sep="") \}

\# Loop through all plots;

\# Note: the following code is not documented in detail, but it is assumed that

\# required information can be obtained by running the code line by line and

\# examining the results

for (ithplot in $1: \operatorname{dim}(\mathrm{n})[1])$ \{

\# First, produce vectors of distr.params used for generating tree lists.

\# Vectors simulsh (shape), simulsc (scale), simuln (number of trees)

\# will include four distinct parameter values (true, lin.int1, itd, lin.int2)

\# where lin.int denotes results by linear interpolation. Additional vectors

\# simulmethod and simulcase provide labels that can be used for identification. simulmethod <- "true"

simulcase $<-1$

simulsh <- shape[ithplot, 2] \# true values

simulsc $<-$ scale[ithplot, 2]

simuln $<-n[$ ithplot, 2$]$

\# Produce extended set of distribution parameters by means of lin.int.

simulmethod <- c(simulmethod, rep(names(n)[3], len=4) [-1] )

simulcase <- c(simulcase, seq $(1,4$, len=4) $[-1])$

simulsh <- c(simulsh, seq(shape[ithplot,2], shape[ithplot,3] + (shape[ithplot,3]shape [ithplot, 2])/2, len=4) [-1])

simulsc <- c(simulsc, seq(scale[ithplot,2], scale[ithplot, 3] + (scale[ithplot,3]-

scale [ithplot, 2])/2, len=4) [-1])

simuln <- c(simuln, seq(n[ithplot, 2], n[ithplot, 3] + (n[ithplot, 3]-

$\mathrm{n}[$ ithplot, 2])/2, len=4) [-1])

\# NB: The linear interpolation method above can produce negative parameter values.

\# Currently it happens rarely and only with the lowest accuracy (extrapolation for

\# forests where ITD distributions are already far apart from field reference ones).

\# The following conditions are to eliminate this problem - as a result, the

\# negative parameter values are set back to those corresponding the ITD values. simulsh [which $(\operatorname{simuln}<0)]<-$ shape [ithplot,3]

simulsc [which $(\operatorname{simuln}<0)]<-$ scale[ithplot, 3]

simuln[which $($ simuln<0) ] $<-$ n[ithplot, 3] 
\# Discretize continuous distribution functions and complete tree lists

for (ithcase in 1:length(simulcase)) \{

treed.list $<-c()$

ntree $<-1$

dperc $<-0$

while (ntree < simuln[ithcase] ) \{

dperc <- dperc+0.01

pweib <- pweibull (dperc, simulsh[ithcase], simulsc[ithcase]) *

simuln [ithcase]

if (pweib > ntree) \{

treed.list <-c(treed.list, rep(dperc, ceiling(pweib-ntree)))

ntree <- ntree + ceiling (pweib-ntree)

$$
\text { \} }
$$

if (ithcase==1) \{

treelist <- cbind(n[ithplot,1], simulmethod[ithcase], simulcase[ithcase], round (treed.list, 2))

\} else \{

treelist <- rbind(treelist, cbind(n[ithplot,1], simulmethod[ithcase], simulcase[ithcase], round(treed.list,2)) )

\}

\}

if (lmfor.available) \{

treelist <- cbind(treelist, round(HDnaslund( as.numeric(treelist[, 4]) , naslund.a, naslund.b),2) )

\} else \{

break \# cannot complete the tree list (tree heights) without lmfor package \}

treelist.final <- cbind(apply(treelist,1,helpf), seq(1:dim(treelist)[1]), rep (1,dim(treelist)[1]), treelist[,4], treelist[,5])

\# Consider only diameters $>=5 \mathrm{~cm}$, because growth model is formulated this way

treelist.final <- treelist.final[which(as.numeric(treelist.final [, 4])>=5), ]

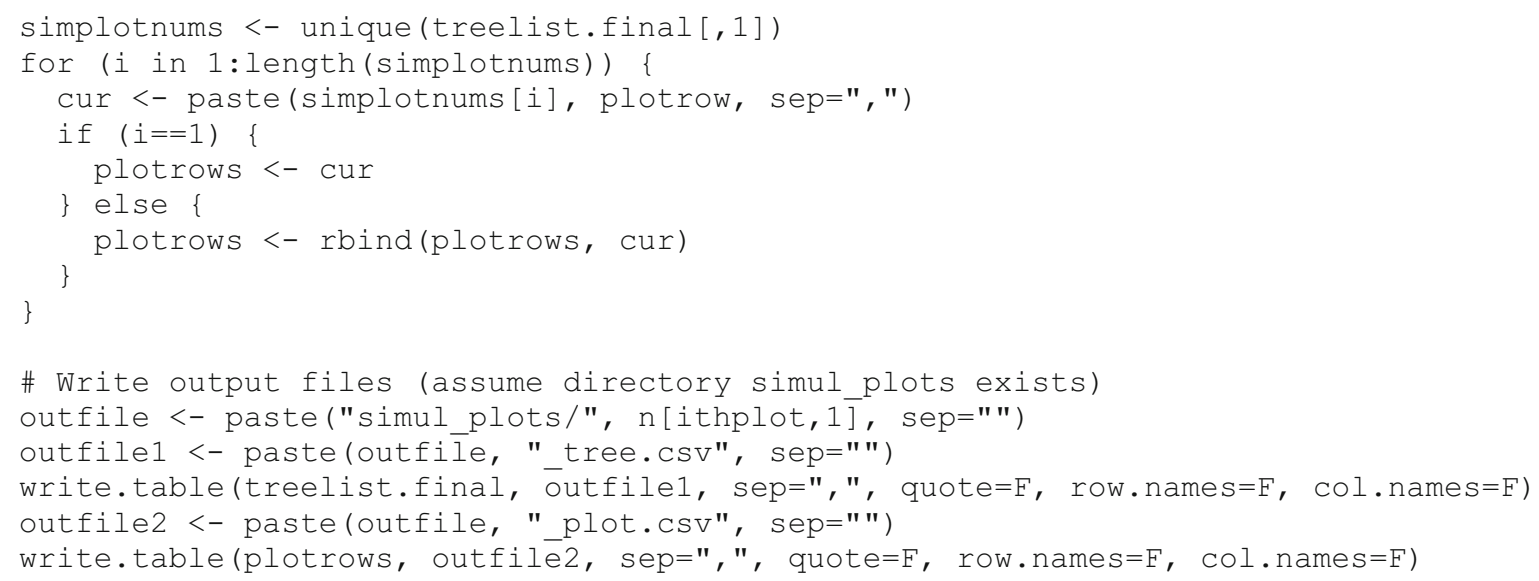




\section{Annex 2}

Table 1 Input distribution parameters: plot identifier, number of trees/ ha (frequencies; $n$ ), and Weibull shape and scale parameters. Suffix field indicates the number of trees and Weibull distribution parameter fitted to the field measurements, whereas itd indicates the corresponding values resulting from a modeling chain based on individual tree detection from airborne laser scanning data (Vauhkonen and Mehtätalo 2015)

\begin{tabular}{|c|c|c|c|c|c|c|}
\hline Plot & n.field & n.itd & shape.field & shape.itd & scale.field & scale.itd \\
\hline 1 & 850 & 625 & 3.5719524295879 & 10.9109790130696 & 19.4128777125947 & 21.7471152382655 \\
\hline 2 & 1100 & 725 & 2.75836464451599 & 10.2090270605235 & 18.400938772738 & 22.398321724941 \\
\hline 3 & 900 & 575 & 2.21360095951749 & 8.17636582321204 & 19.7047696848036 & 24.8819473841455 \\
\hline 4 & 550 & 375 & 2.55533113272705 & 10.3243590821458 & 25.0550484359941 & 30.3379293001165 \\
\hline 5 & 2225 & 1325 & 3.56465818311216 & 5.39983146935897 & 12.7802549052165 & 15.502862425551 \\
\hline 6 & 1625 & 900 & 2.32207649849157 & 5.67111179953996 & 14.8691150243334 & 19.0035166131787 \\
\hline 7 & 1525 & 925 & 2.44019393523567 & 4.63015149559959 & 11.8961941105284 & 14.3211479106969 \\
\hline 8 & 1925 & 1325 & 3.25916122115109 & 7.00124805858673 & 15.0390923376501 & 17.232859184033 \\
\hline 9 & 1125 & 450 & 2.15250614473124 & 4.79228797085343 & 18.4325333652069 & 24.8589648133908 \\
\hline 10 & 2025 & 1125 & 3.77164564178171 & 7.09580186674647 & 15.0765991273711 & 18.3538608059218 \\
\hline 11 & 1375 & 950 & 3.78208880525351 & 6.29869277414385 & 16.1214386465789 & 16.774037784593 \\
\hline 12 & 1625 & 725 & 1.93179144758497 & 6.20372963696403 & 15.2039811908027 & 20.4747472423109 \\
\hline 13 & 1050 & 675 & 2.75281818622303 & 4.40267568871005 & 13.8223486847285 & 16.0710106779134 \\
\hline 14 & 1050 & 675 & 2.50786490937135 & 5.5595345272454 & 13.8024227433264 & 16.1220728949167 \\
\hline 15 & 550 & 525 & 5.70103859461575 & 8.90793269252555 & 17.8081412511655 & 16.1593789250427 \\
\hline 16 & 850 & 700 & 3.8522278369368 & 7.58884875901996 & 19.0595949180265 & 18.283693598239 \\
\hline 17 & 875 & 700 & 3.87974080565483 & 7.4419152073873 & 19.4406618111844 & 19.6704664521616 \\
\hline 18 & 1150 & 650 & 2.89840848401535 & 10.3429132643046 & 15.7550420374084 & 18.2167695218761 \\
\hline 19 & 2125 & 800 & 1.56883124621479 & 4.29724667031254 & 11.6326327778733 & 17.0989618274552 \\
\hline 20 & 1775 & 700 & 1.75760959323564 & 3.96774719047321 & 11.8296837233835 & 16.5493465205612 \\
\hline 21 & 1425 & 650 & 1.3175061743845 & 10.0182591692838 & 15.50716239144 & 25.4084518273024 \\
\hline 22 & 850 & 475 & 1.89929742342348 & 6.03437140161046 & 18.3750343423837 & 25.0888984360887 \\
\hline 23 & 625 & 450 & 2.00288330571137 & 4.20690907197122 & 18.7731786856594 & 22.6679380849074 \\
\hline 24 & 1875 & 450 & 0.936636502389181 & 6.48507517098476 & 8.46144986027225 & 25.9752533353158 \\
\hline 25 & 400 & 350 & 4.49971474692737 & 6.11779645502338 & 23.347866480809 & 24.6495225066384 \\
\hline 26 & 575 & 450 & 2.27414147441238 & 4.75262014921947 & 16.7410971290458 & 16.1356473371122 \\
\hline 27 & 1800 & 975 & 3.32501484118391 & 6.2254885488251 & 15.9177394379845 & 18.3785669742529 \\
\hline 28 & 2250 & 1250 & 3.35899257293905 & 5.5102330430974 & 14.2967232702083 & 17.1865714720803 \\
\hline 29 & 2125 & 1025 & 2.53100119759229 & 6.21656117992352 & 12.9384871284779 & 16.8448024371889 \\
\hline 30 & 900 & 800 & 4.4945381164676 & 6.5952195459202 & 17.2580823636728 & 17.1474881818816 \\
\hline 31 & 1050 & 750 & 3.22069457090112 & 8.65529561769681 & 14.6722951849732 & 16.3509975025995 \\
\hline 32 & 2025 & 925 & 2.12237878617773 & 4.2813311667986 & 11.3729554101231 & 14.8021948848024 \\
\hline 33 & 975 & 625 & 2.34000299565324 & 5.46362270402606 & 17.5487670072524 & 20.6797432365987 \\
\hline 34 & 575 & 500 & 3.88881541082774 & 5.95759173494259 & 25.2752878533956 & 24.5844489987519 \\
\hline 35 & 800 & 550 & 2.50817517938895 & 5.61190754685947 & 20.4608901698771 & 24.9323633132505 \\
\hline 36 & 575 & 425 & 3.24963390281566 & 8.38864551103624 & 23.3628747486636 & 25.7377522919541 \\
\hline 37 & 875 & 675 & 2.61443166052549 & 8.02562717318443 & 20.278351066382 & 22.6385728462688 \\
\hline 38 & 450 & 425 & 4.48720695765417 & 5.20441285123831 & 26.8461250285707 & 26.0103018389265 \\
\hline 39 & 825 & 675 & 3.69474607340216 & 9.2986735665964 & 21.1255343891463 & 22.184563333395 \\
\hline 40 & 1700 & 1075 & 3.06256780762379 & 5.49310612218173 & 11.7262266937824 & 12.9957686160546 \\
\hline
\end{tabular}


Open Access This article is licensed under a Creative Commons Attribution 4.0 International License, which permits use, sharing, adaptation, distribution and reproduction in any medium or format, as long as you give appropriate credit to the original author(s) and the source, provide a link to the Creative Commons licence, and indicate if changes were made. The images or other third party material in this article are included in the article's Creative Commons licence, unless indicated otherwise in a credit line to the material. If material is not included in the article's Creative Commons licence and your intended use is not permitted by statutory regulation or exceeds the permitted use, you will need to obtain permission directly from the copyright holder. To view a copy of this licence, visit http://creativecommons.org/licenses/by/4.0/.

\section{References}

Bergseng E, Ørka HO, Næsset E, Gobakken T (2015) Assessing forest inventory information obtained from different inventory approaches and remote sensing data sources. Ann For Sci 72:33-45

Bourgeois W, Binkley C, LeMay V, Moss I, Reynolds N (2018) British Columbia forest inventory review panel technical background report. Office of the Chief Forester Division, British Columbia Ministry of Forests, Lands, Natural Resource Operations and Rural Development, Canada. https://www2.gov.bc.ca/assets/gov/ farming-natural-resources-and-industry/forestry/stewardship/forestanalysis-inventory/brp_technical_document_final.pdf. Accessed 3 May 2019

Cajander AK (1926) The theory of forest types. Acta For Fenn 29:1-108

Čugunovs M, Tuittila ES, Sara-Aho I, Pekkola L, Kouki J (2017) Recovery of boreal forest soil and tree stand characteristics a century after intensive slash-and-burn cultivation. Silva Fenn 51:7723. https://doi.org/10.14214/sf.7723

Duncanson LI, Cook BD, Hurtt GC, Dubayah RO (2014) An efficient, multi-layered crown delineation algorithm for mapping individual tree structure across multiple ecosystems. Remote Sens Environ 154:378-386

Eerikäinen K, Miina J, Valkonen S (2007) Models for the regeneration establishment and the development of established seedlings in uneven-aged, Norway spruce dominated stands of southern Finland. For Ecol Manag 242:444-461

Eyvindson KJ, Petty AD, Kangas AS (2017) Determining the appropriate timing of the next forest inventory: incorporating forest owner risk preferences and the uncertainty of forest data quality. Ann For Sci 74:2-10. https://doi.org/10.1007/s13595-016-0607-9

Falkowski MJ, Smith AMS, Gessler PE, Hudak AT, Vierling LA, Evans JS (2008) The influence of conifer forest canopy cover on the accuracy of two individual tree measurement algorithms using lidar data. Can J Remote Sens 34:S338-S350

Giannetti F (2017) 3D remote sensing technologies for precision forestry. Dissertation, Università degli Studi di Firenze. https://flore.unifi.it/ retrieve/handle/2158/1131942/344618/. Accessed 3 May 2019

Haara A, Kangas A, Tuominen S (2019) Economic losses caused by tree species proportions and site type errors in forest management planning. Silva Fenn 53:10089. https://doi.org/10.14214/sf.10089

Haight RG, Monserud RA (1990a) Optimizing any-aged management of mixed-species stands. I. Performance of a coordinate-search process. Can J For Res 20:15-25

Haight RG, Monserud RA (1990b) Optimizing any-aged management of mixed-species stands. II. Effects of decision criteria. For Sci 36:125-144

Hou Z, Xu Q, Vauhkonen J, Maltamo M, Tokola T (2016) Speciesspecific combination and calibration between area-based and treebased diameter distributions using airborne laser scanning. Can J For Res 46:753-765
Kangas AS (1998) Uncertainty in growth and yield projections due to annual variation of diameter growth. For Ecol Manag 108:223-230

Kangas AS (2010) Value of forest information. Eur J For Res 129:863874

Kangas A, Eid T, Gobakken T (2014) Valuation of airborne laser scanning based forest information. In: Maltamo M, Næsset E, Vauhkonen $\mathrm{J}$ (eds) Forestry applications of airborne laser scanning - concepts and case studies, Managing Forest ecosystems, vol 27. Springer, Dordrecht, pp 315-331

Kangas A, Gobakken T, Puliti S, Hauglin M, Næsset E (2018a) Value of airborne laser scanning and digital aerial photogrammetry data in forest decision making. Silva Fenn 52:9923. https://doi.org/10. $14214 /$ sf.992

Kangas A, Hartikainen M, Miettinen K (2015) Simultaneous optimization of harvest schedule and data quality. Can J For Res 45:1034 1044

Kangas A, Korhonen KT, Packalen T, Vauhkonen J (2018b) Sources and types of uncertainties in the information on forest-related ecosystem services. For Ecol Manag 427:7-16

Kangas A, Mehtätalo L, Mäkinen A, Vanhatalo K (2011) Sensitivity of harvest decisions to errors in stand characteristics. Silva Fenn 45: 693-709

Kansanen K, Vauhkonen J, Lähivaara T, Seppänen A, Maltamo M, Mehtätalo L (2019) Estimating forest stand density and structure using Bayesian individual tree detection, stochastic geometry, and distribution matching. ISPRS J Photogramm Remote Sens 152:6678

Koch B, Kattenborn T, Straub C, Vauhkonen J (2014) Segmentation of forest to tree objects. In: Maltamo M, Næsset E, Vauhkonen J (eds) Forestry applications of airborne laser scanning - concepts and case studies, Managing Forest ecosystems, vol 27. Springer, Dordrecht, pp 89-112

Köhl M, Baldauf T (2012) Resource assessment techniques for continuous cover forestry. In: Pukkala T, von Gadow K (eds) Continuous cover forestry, Managing Forest ecosystems, vol 23. Springer, Dordrecht, pp 273-291

Laasasenaho J (1982) Taper curve and volume equations for pine spruce and birch. Comm Inst For Fenn 108:1-74

Laiho O, Lähde E, Pukkala T (2011) Uneven-vs even-aged management in Finnish boreal forests. Forestry 84:547-556

Larsen M, Eriksson M, Descombes X, Perrin G, Brandtberg T, Gougeon F (2011) Comparison of six individual tree crown detection algorithms evaluated under varying forest conditions. Int J Remote Sens 32:5827-5852

Lindberg E, Holmgren J (2017) Individual tree crown methods for 3D data from remote sensing. Cur For Rep 3:19-31

Maltamo M, Packalen P (2014) Species-specific management inventory in Finland. In: Maltamo M, Næsset E, Vauhkonen J (eds) Forestry applications of airborne laser scanning - concepts and case studies, Managing Forest ecosystems, vol 27. Springer, Dordrecht, pp 241 252

Mäkinen A, Holopainen M, Kangas A, Rasinmäki J (2010) Propagating the errors of initial forest variables through stand-and tree-level growth simulators. Eur J For Res 129:887-897

Mäkinen A, Kangas A, Nurmi M (2012) Using cost-plus-loss analysis to define optimal forest inventory interval and forest inventory accuracy. Silva Fenn 46:211-226

Mauro Gutiérrez F, Frank B, Monleon VJ, Temesgen H, Ford K (2019) Prediction of diameter distributions and tree-lists in southwestern Oregon using LiDAR and stand-level auxiliary information. Can J For Res 49:775-787

Mehtatalo L (2017) lmfor: functions for Forest biometrics. R package version 1.2. https://CRAN.R-project.org/package=lmfor. Accessed 3 May 2019

Næsset E (2014) Area-based inventory in Norway - from innovation to an operational reality. In: Maltamo M, Næsset E, Vauhkonen J (eds) 
Forestry applications of airborne laser scanning - concepts and case studies, Managing Forest ecosystems, vol 27. Springer, Dordrecht, pp 215-240

Nieminen M, Hökkä H, Laiho R, Juutinen A, Ahtikoski A, Pearson M, Kojola S, Sarkkola S, Launiainen S, Valkonen S, Penttilä T, Lohila A, Saarinen M, Haahti K, Mäkipää R, Miettinen J, Ollikainen M (2018) Could continuous cover forestry be an economically and environmentally feasible management option on drained boreal peatlands? For Ecol Manag 424:78-84

Pascual Arranz A (2018) Improving forest management planning by means of airborne laser scanning and dynamic treatment units based on spatial optimization. Dissertationes Forestales 257, $60 \mathrm{p}$

Pascual C, García-Montero LG, Arroyo LA, García-Abril A (2013) Increasing the use of expert opinion in forest characterisation approaches based on LiDAR data. Ann For Sci 70:87-99

Peuhkurinen J, Maltamo M, Malinen J, Pitkänen J, Packalén P (2007) Preharvest measurement of marked stands using airborne laser scanning. For Sci 53:653-661

Peuhkurinen J, Mehtätalo L, Maltamo M (2011) Comparing individual tree detection and the area-based statistical approach for the retrieval of forest stand characteristics using airborne laser scanning in Scots pine stands. Can J For Res 41:583-598

Peura M, Burgas D, Eyvindson K, Repo A, Mönkkönen M (2018) Continuous cover forestry is a cost-efficient tool to increase multifunctionality of boreal production forests in Fennoscandia. Biol Conserv 217:104-112

Pitkänen J (2005) A multi-scale method for segmentation of trees in aerial images. In: Hobbelstad K (ed) Proceedings of the SNS Meeting at Sjusjøen - Forest Inventory and Planning in Nordic Countries, Norway, 6-8 September 2004. Norwegian Institute of Land Inventory, pp 207-216.

Pitkänen J, Maltamo M, Hyyppä J, Yu X (2004) Adaptive methods for individual tree detection on airborne laser based canopy height model. In: Theis M, Koch B, Spiecker H, Weinacker H (eds) Proceedings of ISPRS working group VIII/2: laser-scanners for Forest and landscape assessment. University of Freiburg, Freiburg, pp 187-191

Pukkala T (2005) Metsikön tuottoarvon ennustemallit kivennäismaan männiköille, kuusikoille ja rauduskoivikoille (in Finnish for "Prediction models for the expectation value of pine, spruce and birch stands on mineral soils"). Metsätieteen Aikakauskirja 3(2005):311-322

Pukkala T (2016a) Plenterwald, Dauerwald, or clearcut? Forest Policy Econ 62:125-134

Pukkala T (2016b) Which type of forest management provides most ecosystem services? For Ecosyst 3:9-16. https://doi.org/10.1186/ s40663-016-0068-5

Pukkala T (2018) Instructions for optimal any-aged forestry. Forestry 91 : $563-574$

Pukkala T, Lähde E, Laiho O (2009) Growth and yield models for uneven-sized forest stands in Finland. For Ecol Manag 258:207-216

Pukkala T, Lähde E, Laiho O (2014a) Optimizing any-aged management of mixed boreal forest under residual basal area constraints. J For Res 23:727-636

Pukkala T, Lähde E, Laiho O (2015) Which trees should be removed in thinning treatments? For Ecosyst 2:32-12. https://doi.org/10.1186/ s40663-015-0056-1
Pukkala T, Miina J (1998) Tree-selection algorithms for optimizing thinning using a distance-dependent growth model. Can J For Res 28: 693-702

Pukkala T, Packalén P, Heinonen T (2014b) Dynamic treatment units in forest management planning. In: Borges JG, Diaz-Balteiro L, McDill ME, Rodriguez LCE (eds) The management of industrial forest plantations, Managing Forest ecosystems, vol 33. Springer, Dordrecht, pp 373-392

Rummukainen A, Alanne H, Mikkonen E (1995) Wood procurement in the pressure of change: resource evaluation model till year 2010 . Acta For Fenn 248:1-98

Ruotsalainen R, Pukkala T, Kangas A, Vauhkonen J, Tuominen S, Packalen P (2019) The effects of sample plot selection strategy and the number of sample plots on inoptimality losses in forest management planning based on airborne laser scanning data. Can J For Res 49:1135-1146

Tahvonen O (2009) Optimal choice between even-and uneven-aged forestry. Nat Resour Model 22:289-321

Vastaranta M, Holopainen M, Yu X, Hyyppä J, Mäkinen A, Rasinmäki J, Melkas T, Kaartinen H, Hyyppä H (2011) Effects of individual tree detection error sources on forest management planning calculations. Remote Sens 3:1614-1626

Vauhkonen J (2019) Python v. 2.7 code for comparing theoretical treelevel thinning alternatives of input forest. Version 0.1. Zenodo. [Dataset]. https://doi.org/10.5281/zenodo.2645064

Vauhkonen J, Ene L, Gupta S, Heinzel J, Holmgren J, Pitkänen J, Solberg S, Wang Y, Weinacker H, Hauglin KM, Lien V, Packalén P, Gobakken T, Koch B, Næsset E, Tokola T, Maltamo M (2012) Comparative testing of single-tree detection algorithms under different types of forest. Forestry 85:27-40

Vauhkonen J, Mehtätalo L (2015) Matching remotely sensed and field measured tree size distributions. Can J For Res 45:353-363

Vauhkonen J, Packalen T (2019) Shifting from even-aged management to less intensive forestry in varying proportions of forest land in Finland - impacts on carbon storage, harvest removals, and harvesting costs. Eur J For Res 138:219-238

Vauhkonen J, Pukkala T (2016) Selecting the trees to be harvested based on the relative value growth of the remaining trees. Eur J For Res 135:581-592

Vauhkonen J, Packalen P, Malinen J, Pitkänen J, Maltamo M (2014) Airborne laser scanning based decision support for wood procurement planning. Scand J For Res 29:132-143

Wing BM, Boston K, Ritchie MW (2019) A technique for implementing group selection treatments with multiple objectives using an airborne Lidar-derived stem map in a heuristic environment. For Sci 65:211-222

Xu Q, Hou Z, Maltamo M, Tokola T (2014) Calibration of area based diameter distribution with individual tree based diameter estimates using airborne laser scanning. ISPRS J Photogramm Remote Sens 93:65-75

Publisher's note Springer Nature remains neutral with regard to jurisdictional claims in published maps and institutional affiliations. 